\title{
CONNECTING THE UPROOTED: PARENTS' USE OF BI-CULTURAL SOCIALIZATION IN FACILITATING TRANSNATIONALISM AMONG CHINESE ADOPTEES
}

by

Meaghan Symington, BA, McMaster University, 2010

\begin{abstract}
A Major Research Paper
presented to Ryerson University

in partial fulfillment of the requirements for the degree of

Master of Arts

in the Program of Immigration and Settlement Studies
\end{abstract}

Toronto, Ontario, Canada, 2012

(c) Meaghan Symington 2012 


\section{AUTHOR'S DECLARATION}

AUTHOR'S DECLARATION FOR ELECTRONIC SUBMISSION OF A MAJOR RESEARCH PAPER

I hereby declare that I am the sole author of this Major Research Paper. This is a true copy of the Major Research Paper, including any required final revisions, as accepted by my examiners.

I authorize Ryerson University to lend this Major Research Paper to other institutions or individuals for the purpose of scholarly research

I further authorize Ryerson University to reproduce this Major Research Paper by photocopying or by other means, in total or in part, at the request of other institutions or individuals for the purpose of scholarly research.

I understand that my Major Research Paper may be made electronically available to the public. 


\title{
CONNECTING THE UPROOTED: PARENT'S USE OF BI-CULTURAL SOCIALIZATION IN FACILITATING TRANSNATIONALISM AMONG CHINESE ADOPTEES
}

\author{
Meaghan Symington \\ Master of Arts, 2012 \\ Immigration and Settlement Studies \\ Ryerson University
}

\begin{abstract}
This Major Research Paper explores the distinct form of transnationalism experienced by Chinese adoptees in Canada by examining adoptive parents' use of bi-cultural socialization mechanisms. In doing so, this paper addresses the ways in which parents utilize cultural exposure to facilitate internal community ties and transnational connections between their children and China. The researcher attempts to present a link between parents' fostering of cultural knowledge and a resulting unique form of transnationalism that is not initially established or maintained through the efforts of the immigrant population (Chinese adoptee community). A qualitative research approach was undertaken through a purposive sampling technique, self-selection and elite interview data. Data was collected through in-depth one-on-one interviews with eight parents of adopted daughters from China. Through analysis of this empirical interview data and a theoretical reliance on the post-colonial paradigm of intercountry adoption, it was determined that Chinese adoptees in Canada experience and are attached to two or more places simultaneously.
\end{abstract}

Key words:

Chinese Adoptees, Intercountry Adoption, Transnationalism, Bi-Cultural Socialization, Postcolonial Paradigm. 


\section{ACKNOWLEDGEMENTS}

I wish to thank Dr. Francis Hare for supervising with patience and enthusiasm. Thank you for allowing me to pursue a research interest without intervention. Your insight and helpful suggestions were invaluable.

I would also like to extend my gratitude to Cindy Boates, President of the Toronto chapter of Families With Children From China, for generously assisting with the recruitment process. Your support provided a significant stress-relief when it felt like time was not on my side.

So many thanks to my friends and family who continued to offer kind words of encouragement week after week. Lastly, thank you to SL for your tireless editing, draft after draft. 


\section{TABLE OF CONTENTS}

INTRODUCTION

THEORETICAL PERSPECTIVE: TRANSNATIONALISM AND THE POST-COLONIAL PARADIGM

REVIEW OF THE LITERATURE

The Traditional Closed System of Intercountry Adoption: "Clean Break" Model 6

Domestic Policy and International Conventions 9

Intercountry Adoption in China $\quad 11$

Chinese Adoptees as a Unique Diaspora 12

RESEARCH METHODS $\quad 17$

$\begin{array}{ll}\text { Recruitment and Sample } & 21\end{array}$

$\begin{array}{ll}\text { Analysis of Data } & 23\end{array}$

\begin{tabular}{ll} 
FINDINGS & 24 \\
\hline
\end{tabular}

Birth Roots 26

Family and Individual Identity 29

Interpersonal Chinese Associations $\quad 32$

Cultural Encounters $\quad 35$

In-Group Community Ties

Learning from Closed Adoption $\quad 40$

Interracial Family: Influence of a Chinese Mother 42

DISCUSSION $\quad 44$

Parents' Attitudes Towards Bi-Cultural Socialization $\quad 44$

Bi-Cultural Socialization Mechanisms Pursued 48

$\begin{array}{ll}\text { Transnational Ties } & 51\end{array}$

LIMITATIONS AND SUGGESTIONS FOR FURTHER RESEARCH

\begin{tabular}{ll} 
CONCLUSION & 59 \\
\hline
\end{tabular}

\begin{tabular}{ll} 
APPENDICES & 63 \\
\hline Appendix
\end{tabular}

Appendix A: Participant Recruitment Letter 63

Appendix B: Recruitment Poster $\quad 65$

Appendix C: Interview Guide $\quad 66$

\begin{tabular}{ll} 
BIBLIOGRAPHY & 68 \\
\hline
\end{tabular} 


\section{Introduction}

This research paper explores the distinct form of transnationalism experienced by Chinese adoptees in Canada by examining the intercountry adoption process in China, Canadian immigration policy, international conventions, and the role of adoptive parents in cultural maintenance. In doing so, this research will expand on relevant literature by introducing an important analysis of the relationship between these actors and their influence on the ability of Chinese adoptees to establish a diasporic community. Although the migration of children for the purpose of adoption is rarely examined through the lens of Canadian family class immigration or diasporic studies, some research (Dorow, 2006; Miller-Loessi and Kilic, 2001; Quiroz, 2008; Selmen, 2002, 2006; Tan and Nakkula, 2008; Volkman, 2003) has revealed that international adoptees tend to display many aspects of transnationalism common to other immigrant groups. This is exemplified by the large community of Chinese adoptees in Canada who have migrated in significant numbers since the Chinese government began its intercountry adoption program in 1992.

Canadian families adopted 7,982 children from China between the years 1999 and 2009 (Citizenship and Immigration Canada, 2011). Many of these children meet Hiebert's (2000) understanding of immigrant transnationalism as those who "experience and are attached to two or more places simultaneously" (p, 5). Hiebert (2000) claims that diasporic groups develop identities based on movement and connections across space rather than exclusive associations with specific places. This is true of Chinese adoptees holding multiple concepts of self-identity based on connections with the dominant culture in which they have been raised, as well as the social and cultural practices within their country of origin. However, 
Canada's Chinese adoptee diaspora differs from the Chinese immigrant population because the creation and maintenance of transnational ties are largely the result of adoptive parents' efforts to promote their child's birth culture. This distinctive characteristic makes Chinese adoptees an exceptional diasporic group; differentiated from the traditional understanding of immigrant-initiated transnationalism, while retaining similarities in their maintenance of connections to the homeland.

Children who are adopted from foreign countries and brought to Canada are classified as immigrants in a category entitled "Immigration for Social Purposes." As such, they are granted permanent resident status but do not immediately receive Canadian citizenship (Worotynec, 2006). According to Dorrow and Lepatsky (2006), intercountry adoption is an exceptional form of Canadian family class immigration because the immigrant (adopted child) can no longer have legal ties to his/her biological family. This is significantly different from the experiences of other transnational immigrant groups who frequently keep in close contact with their family members and friends residing in the homeland. Intercountry adoption also differs from most other cases of family sponsorship because the immigrant does not choose to migrate, but rather, is chosen for immigration (Dorrow and Lepatsky, 2006). Consequently, many scholars (Dorrow and Lepatsky, 2006; Lee, 2008; Tan and Nakkula, 2008; Tessler et al., 1999; Volkman 2003) perceive intercountry adoptees as members of diasporic communities that have been established as a result of involuntary displacement form their country of birth.

Given that their migration typically occurs when they are infants, children who enter Canada as international adoptees may not have intrinsic ties to the homeland in the same way that many other immigrants do. Exposure to their birth culture and norms is generally limited 
before arriving to Canada. Therefore, adoptive parents need to decide the degree and means in which they will expose their child to the culture of their country of origin. Jacobson (2008) uses the term "culture keeping" to describe adoptive parents' attempts to ensure that their children have access to their ethnic pasts. Similarly, Carstens and Juliá (2000) define ethnoracial awareness in intercountry adoption as a "conscious valuing of socially transmitted behaviour patterns, arts, beliefs, language, institutions, history, and other artifacts characteristic of the child's country of origin" (p.62). Dorrow's (2006) research on the adoption of Chinese children in North America has demonstrated that family involvement in cultural activities vary widely. Some parents actively attempt to immerse their child in the culture of his or her birth country, while others do not mention the child's ethnicity or cultural background at all.

The unique form of transnationalism experienced by intercountry adoptees is an important area of research because since the mid 1990s, between 1,800 and 2,200 internationally adopted children have migrated to Canada each year (Worotynec, 2006). Although, such adoptions only represent two percent of the total immigration flow, the diaspora of international adoptees is growing and their experiences warrant examination. In addition, this is a significant area of research because intercountry adoption expands the scope of transnationalism to include individuals who were too young during the time of migration to possess significant memories of the homeland. As a result, this research reveals that transnational networks are not solely dependent on links with friends and family, economic ties, or political and social involvement in the country of origin. Consequently, recognizing Chinese adoptees as a transnational diaspora in Canada demonstrates that it is possible to be 
attached to two or more places simultaneously without being socialized in more than one country.

\section{Theoretical Perspective: Transnationalism and the Postcolonial Paradigm}

Over the past three decades, as the Canadian policy on multiculturalism has evolved, there has been a greater emphasis on encouraging immigrants to engage in transnational social practices. The transnational perspective conceptualizes many contemporary immigrants not as "uprooted" or as having completely left behind their "old" countries but as maintaining multiple links and networks with their homelands (Wong and Satzewich, 2006). In a globalizing world, individuals and institutions have multiple linkages and interactions that cross borders of nation states (Wong and Satzewich, 2006). Advances in communications and transportation technology have facilitated these linkages. According to Preston et al. (2006), transnational ties "shape social connections and position people in networks and organizations that link two or more geographically distinct principles in different nation-states" (p. 92). Similarly, Waddington (2011) utilizes postcolonial theories of cultural hybridity to note that cultures are interrelated and develop not in isolation, but through interaction. Hence, both the postcolonial paradigm and the concept of transnationalism reject the common practice of equating culture with geographical location.

Transnational activities can take various forms and occur with varying intensity. They include economic, social, political, cultural and emotional connections that link individuals across geographical boundaries. Related to this concept is the term 'diaspora', originating from the Greek word, 'diaspeirein' and referring to "a fruitful scattering away of seeds' (Miller-Loessi \& Kilic, 2001). Wong and Satzewich (2006) define diasporas as communities that satisfy a minimum of three criteria: the population is dispersed from a homeland to two or 
more other territories; their presence abroad is enduring, although exile is not necessarily permanent, with those in the diaspora possibly moving between homeland and receiving country; and there is some form of exchange between or among spatially separated populations. Many internationally adopted children meet this understanding of diasporic communities because they have been involuntarily scattered to the 50 countries participating in intercountry adoption, while simultaneously maintaining their cultural roots and sustaining emotional, cultural and social connections with their homeland.

Members of transnational diasporic communities experience dual or multiple identities characterized by hybridity. Correspondingly, the postcolonial paradigm of intercountry adoption supports attempts to integrate the multiple cultural influences that make up an adoptive child's unique sense of personal identity. It rejects the "clean break" model of adoption, as that approach marginalizes the child's birth heritage and emphasizes assimilation over cultural hybridity (Waddington, 2011). Instead, the postcolonial paradigm of intercountry adoption regards incorporation into the receiving country and transnational practices as simultaneous processes. Levitt et al. (2003) contend that migrants have the ability to "configure packages of livelihood strategies, piecing together opportunities in their sending and receiving countries to reap the greatest rewards" (p. 571). Similarly, the postcolonial paradigm celebrates cultural diversity while resisting imperial notions of cultural difference, in which one cultural identity is acknowledged above another (Waddington, 2011).

The postcolonial paradigm for intercountry adoption encourages sending countries to establish a cultural presence in prominent receiving countries and provide cultural resources to adopted children and their parents. By doing so, the sending country locates its cultural heritage beyond the physical boundaries of the nation state (Waddington, 2011). This is 
similar to the common process in which immigrants create new social organizations that link their places of origin with the destinations where they have settled. Preston et al. (2006) argue that as a result of these efforts, newcomers transform the receiving community through demands for new social services and the implementation of new ideas transferred from their country of origin. In the case of intercountry adoption, this transformation is evident by a new industry to support adoptive parents in their attempts to socialize their children while utilizing aspects of their birth culture. Jacobson (2008) notes that online adoption shops and malls provide parents with Asian dolls, Korean textbooks, Russian Christmas ornaments, Chinese CDs, and ethnic home décor and toys.

\section{Review of the Literature}

\section{The Traditional Closed System of Intercountry Adoption: "Clean Break" Model}

The migration of children for adoption to North America has paralleled overall migration patterns with early adoptees originating from countries in Europe and more recent adoptees coming largely from developing counties in Latin America and Asia (Bergquist, 2003; Dorow and Lepatsky, 2006; Lovelock, 2000; Miller-Loessi and Kilic, 2001; Selman, 2002, 2006, 2009). Selman (2009) notes that intercountry adoption began as a North American response to the devastation in Europe during and after World War II. During this time period, couples generally adopted internationally because of humanitarian concerns for children who had been orphaned or neglected due to war. In the early post-war period, the prominent countries of origin among international adoptees were those who had been defeated, including Greece, Italy, Germany, and Japan (Selman, 2002). In contrast to the present situation where perspective parents are actively seeking orphaned or abandoned children, the ultimate goal during the post-war period was finding families for the large 
number of displaced orphans. Hence, Lovelock (2000) has categorized the history of intercountry adoption into two waves: the first consists of the period between World War II and the mid 1970s when emphasis was placed on "finding families for children" and the second covers the timeframe from the mid 1970s to the present period, where the focus has shifted to "finding children for families" (p. 908).

Due to the long-term social and economic impacts of the Korean War from 1950 to 1953, the second and largest wave of international adoption was of South Korean children. Between 1955 and 1998, it is estimated that 141,000 Korean children were adopted worldwide (Freundlich and Lieberthal, 2000). Many of these children were of mixed race, having Korean mothers and military fathers from North America or Western Europe (Selman, 2002). Freundlich and Lieberthal (2000) state that intercountry adoption became a solution to the growing number of children in institutions who were not accepted in Korean society because of illegitimacy.

When intercountry adoption increased in occurrence during the 1950 s, the traditional closed adoption system and the 'clean break' model was the norm. During the 'clean break' model of intercountry adoption, adoptive parents symbolically replaced birth parents by substituting the cultural identities of the children with those of their new parents. According to Volkman (2003), the "as if begotten" biological family was the goal and a disassociation from the past was achieved by rewriting birth certificates with the names of adoptive parents. Correspondingly, there was a perceived need to sever the child's links with the past, assimilate him or her within their new family and build a fresh cultural identity (O'Halloran, 2009). Generally, the acknowledgement of difference was discouraged because biological kinship was thought to be psychologically beneficial for the child. 
Researchers (Goss, 2010; Freundlich and Lieberthal, 2000; Jacobson, 2008; Volkman, 2003) have explored the ways in which the 'clean break' model of intercountry adoption has influenced Korean adoptees' identity formation through adolescences and adulthood. Volkman's (2003) research reveals that many adult Korean adoptees recall perceiving themselves as Caucasian, like their parents, during childhood. These perceptions often led to further identity conflicts as the adoptees faced outsider inquiries regarding their racial differences. Similarly, Jacobson (2008) cites memoirs, poetry, published anthologies, art and documentaries that expose the confusion and anger many Korean adoptees experienced due to assimilation efforts. Through these works, Korean adoptees have highlighted the ways in which isolation from their birth culture and forced assimilation was damaging to their own self-esteem and to relations with their adoptive families (Jacobson, 2008).

These hardships have had a profound effect on how the adoption community now approaches the socialization of intercountry adoptees. Internationally adopted children from Korea serve as a precursor to children adopted from China because they comprised the first large-scale influx of Asian adoptees into North America. Volkman (2003) argues that in contrast to the isolation and uncertainty articulated in recent years by many Korean adoptees, adopted children from China and their parents have taken advantage of new commercial and institutional resources that are helping to ease adoptive identity difficulties. These institutions include culture camps, play groups, Web sites, reunions, return heritage trips and publications intended for the adoptive community. Additionally, international adoptive parents frequently attend seminars and workshops given by adult adoptees in order to learn about beneficial parenting practices and mistakes to avoid (Jacobson, 2008). Volkman (2003) claims that 
awareness of the Korean experience motivates many adopting parents of Chinese children to foster cultural pride within the family.

\section{Domestic Policy and International Conventions:}

Although in the early phases of intercountry adoption children were expected to cut all physical and emotional ties with their countries of origin, over the last two decades there has been increasing emphasis on the importance of children's birth heritage (Dorow and Lepatsky, 2006). It is now believed that exposure to their culture of origin will help adoptees establish a balanced sense of self-identity that will be beneficial to their overall social, psychological, and academic wellbeing (Jacobson, 2008). These concerns are reinforced through international conventions such as the United Nations Convention on the Rights of the Child (1989) and the Hague Convention on Protection of Children and Cooperation in Respect of Intercountry Adoption (1993). Both state that "due regard shall be paid to the desirability of continuity in a child's upbringing and to the child's ethnic, religious, cultural and linguistic background" (Volkman, 2003, p.37). Access to the culture of one's homeland is framed as a birthright of all children. Article 4 of the Hague Convention states that children requiring international adoption placement are "entitled to know and have access to information about their family background and cultural heritage and maintain or develop cultural identity" (The Hague Convention, 1993, p. 152). According to Worotynec's (2006) understanding, this statement is meant to ensure that internationally adopted children are entitled to know who they are, where they come from, and what their birth heritage is.

In addition to international law, the Canadian government has established domestic policies to endorse cultural maintenance among families who pursue intercountry adoption. For example, the Canadian Multiculturalism Act (1971) helps to ensure that international 
adoptees are encouraged to explore their cultural heritage. The Act states that, "persons belonging to ethnic, religious or linguistic minorities shall not be denied the right to enjoy their own culture, to profess and practice their own religion or to use their own language" (Worotynec, 2006). Furthermore, adoption agencies often seek a commitment from prospective adoptive parents to instill and nurture within the adoptee a sense of their culture of origin and not restrict them to the parents' own mono-cultural environment (O'Halloran, 2009). Therefore, both domestic policy and Canadian adoption agency legislation recommend affirming the child's cultural and national heritage as an important part of being an adoptive parent.

Sending countries also have a significant influence over the international adoption process and the degree of emphasis on birth culture. For example, China places stringent licensing requirements on foreign liaison adoption agencies and also requires adopting parents to spend two weeks in the country before receiving their child. Waddington (2011) highlights the benefits of this requirement by arguing that adoption travel trips foster greater cultural exchange and awareness between the families and nations in intercountry adoption. Additionally, Zhang and Lee (2011) claim that most adoptive parents are positive about this forced cultural exposure and are willing to learn more about their child's birth heritage. Having travelled to China themselves, these parents are more aware of the cultural loss that their children are forced to endure while being socialized outside of their birth country. Furthermore, the process of finalizing the adoption occurs under Chinese authority, often in a ritualized Chinese ceremony in which government officials encourage parents to honour and respect their child's heritage (Miller-Loessi and Kilic, 2001).! 


\section{Intercountry Adoption in China:}

China's One-Child Policy is the most significant contributing factor to large-scale intercountry adoption from China. The One-Child Policy was introduced in 1979 to restrain the huge population growth rate and subside fears of an economic downturn. An unintentional outcome of this policy has been a gender preference crisis that has resulted in the extensive rejection of baby girls. Miller-Loessi and Kilic (2001) argue that the patriarchal structure of traditional Chinese society has led to a strong perceived need for at least one son, especially among the rural population. In the absence of social security systems for poor families in rural areas of China, sons are necessary to provide economically and care for aging parents (Miller-Loessi \& Kilic, 2001). Additionally, in much of rural China, married couples live with the husband's parents, rather than setting up an independent household. Daughters become members of her husband's family, where they are expected to support their in-laws when they grow old (Tessler et al., 1999). Consequently, a son is necessary for both the continuity of the family line and financial security of aging parents (Luo and Smolin, 2005). Furthermore, Dowling and Brown (2009) claim that the preference for male children has been enhanced through the further inequalities between the urban and rural populations due to substantial economic growth in China. Rural poverty and mass migration to larger cities have resulted in insufficient welfare support and a real need for male children.

As a consequence of the combination of the One-Child Policy and the common preference for a son, many unwanted baby girls have been left to the care of orphanages. The large increase in abandonment of female children initially overwhelmed China's welfare institutions. In order to reduce the social and financial burden, the Chinese government implemented policies to establish an intercountry adoption program in 1992. For over a 
decade, this system placed between seven to ten thousand children annually (Lue and Smolin, 2005). However, the system of intercountry adoption in China has been unique because most of the abandoned children are females of similar socio-economic origin. In 2001, the number of children residing in orphanages or foster care in China was estimated to be 100,000, and 98 percent were believed to be girls originating from rural areas (Miller-Loessi \& Kilic, 2001). Consequently, Volkman (2003) argues that there has never been another cohort of adoptees arriving in North America in such large numbers who are roughly the same age and mostly the same gender.

Despite its status as a major sending country for international adoptees, in 2006 China began to reduce the number of children available for intercountry adoption. Selman (2009) believes that the sudden reversal was a conscious move by the government through it's central authority, The China Centre for Adoption Affairs (CCAA), after receiving a growing number of applications from single women or couples in same-sex relationships. In 2006, the CCAA announced new guidelines, including a requirement that perspective adoptive parents be heterosexual couples that have been married for at least two years, with no chronic illness or disability, including obesity (Selman, 2009). This policy change has significantly altered the number of Chinese children entering Canada as intercountry adoptees. In 2005, 52.5 percent of all international adoptions to Canada were of Chinese children. By 2009, the proportion had dropped to 21.8 percent (CIC, 2011).

\section{Chinese Adoptees as a Unique Diaspora:}

The process of establishing transnational ties for Chinese adoptees is difficult because the majority arrive in Canada while they are still infants or young children and therefore have limited exposure to Chinese culture and norms. The average age of adoption for children from 
China is between 6 and 36 months (Tan \& Nakkula, 2008). Lee (2006) claims that most displaced people retain memories of their homeland that are often accompanied by a yearning for the place they have left behind. However, this may not be the case for the majority of Chinese adoptees because they do not have extensive memories of their birthplace. Bergquist (2003) expands this argument by stating that since they do not arrive with significant cultural knowledge, the migration of Chinese adoptees is followed by a process of socialization rather than acculturation. Hence, adopted children do not have to adjust or integrate into the dominant society in the same way that most other immigrants do.

Additionally, as most adopting parents of Chinese children in Canada are not Chinese themselves, transnationalism is often difficult for Chinese adoptees to establish and maintain. Dorrow and Lepatsky (2006) claim that intercountry adoption frequently "creates intimate family relations between white non-immigrant parents and non-white immigrant children that come with a birth culture different from that of their adoptive parents" (p. 63). Research (Carstens and Juliá, 2000; Dorrow, 2006; Dorrow and Lepatsky, 2006; Tan and Nakkula, 2008) has shown that these physical and cultural differences make some adoptive children feel disconnected from the family and from mainstream society as a whole. Adopted children who face constant physical reminders of their adoptive status can experience difficulties in establishing a self-identity that acknowledges both their cultural heritage and Canadian upbringing.

Furthermore, Canadian adoptive parents may not have the appropriate resources to assist their children with becoming more familiar with their birth culture. For example, in a study by Tan and Nakkula (2008) on parent's attitudes towards their adopted Chinese daughters' ethnic identity, several parents acknowledged that since they were not socialized 
within a culture of traditional Chinese norms, they found it difficult to teach their children about their Chinese heritage. Thus, socializing a child to be competent in Chinese language, culture and values is a difficult task for many Canadian parents who, unlike Chinese immigrant families, do not possess knowledge to hand down to their children (Tessler et al., 1999).

Regardless of these barriers to immigrant transnationalism, internationally adopted children tend to establish a self-concept that is largely based on multiple associations with more than one culture or ethnicity (Bergquist, 2003; Dorrow, 2006; Lee, 2006; Miller-Loessi and Kilic, 2001; Quiroz, 2008; Volkman, 2003). Lee (2006) expands this argument by claiming that although Chinese adoptees have been displaced into multiple receiving countries without the possibility of returning to the homeland permanently, they have been active in recreating aspects of their culture of origin. Similar to other diasporic groups, Chinese adoptees are finding solidarity with other transnational adoptees through online support groups and adoptive family organizations (Lee, 2006). The community of Chinese adoptees in Canada, both online and through cultural and adoptive organizations is extensive and well connected.

Despite these similarities, the transnational ties of Chinese adoptees are unlike those of many other immigrant communities because connections to China are largely the result of parents' efforts. According to Volkman (2003), many adoptive parents help their Chinese children to establish a balanced sense of cultural identity by pursuing bi-cultural socialization methods. Cultural socialization is a term traditionally used to describe the process in which immigrant families teach cultural pride through customs such as language, cultural activities, and visits to the homeland (Berbery and O'Brien, 2011). Similarly, Oesterle (2006) perceives 
bi-cultural socialization as parents' efforts to communicate multiple cultural values, beliefs, and behaviours to the child, as well as the child's process of internalizing and embracing these messages. Bi-cultural socialization implies some degree of cultural competence which allows children to switch back and forth comfortably as they represent their multiple heritages (Tessler et al., 1999). In order to accomplish this, Jacobson (2008) argues that adoptive parents pursue a process of 'culture keeping' in which they attempt to partially replicate the cultural education internationally adopted children would have received if they were being raised within a family in their country of origin.

Culture keeping and bi-cultural socialization are commonly pursued through surrogate cultural organizations outside of the family. For the Chinese adoptee community in Canada, cultural activities often include language training, martial arts, or dance classes offered through organizations such as the Chinese Cultural Association and China Cultural Camps (Volkman. 2003). Culture camps are designed to teach children about the cultural values and customs of their birth country while also providing an opportunity to meet other international adoptees. Therefore, these types of camps offer information on a children's racial and ethnic heritage while also affording them a sense of normalcy and the knowledge that adoptive families are common (Randolph and Holtzman, 2010). Some adoptive parents provide much greater opportunity for bi-cultural socialization by enrolling their children into integrated schools, developing and maintaining friendships with Chinese individuals, and providing Chinese role models or caregivers for their children (Vonk and Massatti, 2008). These types of resources have the ability to offer cultural learning that most adoptive parents would not be able to provide on their own. Additionally, Jacobson (2008) claims that many parents pursue Chinese cultural activities, speak positively about China, and bring Chinese-related goods into 
their home, in order to establish an appreciation for China that will translate into a positive self-image for their children. In this sense, culture keeping and bi-cultural socialization can also be a strategy to prepare children for encounters with racism by helping them establish a strong sense of cultural identity that can act as a form of protection against discrimination.

Bi-cultural socialization and culture keeping among Chinese adoptive families is also facilitated through the organization Families With Children From China (FCC). FCC is a important resource that has helped internationally adopted children from China to establish transnational ties by providing a network of parental support groups, with over 100 locations in the United States, Canada, and the United Kingdom. As a parent-inspired grassroots organization, FCC lacks a central governing body, and therefore any parent who has adopted a child of Chinese origin can form a local FCC chapter. All FCC chapters share three common goals: "to support families who have adopted from China through post-adoption and Chinese culture programs; to encourage adoption from China and support waiting families; and to advocate for and support children remaining in orphanages in China" (Tessler et al., 1999, p. 61). Through their use of pre-adoption information meetings, newsletters, family picnics, celebrations of Chinese festivals and holidays, and Chinese language and cultural classes, FCC submerges adoptive families into aspects of Chinese culture (Tessler et al., 1999). Waddington (2011) argues that organizations such as FCC serve as a cultural resource for foreign-born adoptees and consequently undermine the assumption that nation-states are the primary and exclusive source for authentic cultural knowledge.

Another increasingly popular method of pursuing bi-cultural socialization and culture keeping is through 'roots trips' or 'heritage tours' in which children reconnect with their homeland. Boates (2008) discusses the emergence of a new specialized travel industry that 
supports adoptive parents' interest in returning to the places where their families were first formed. Since 1995 Our Chinese Daughters Foundation, a Beijing-based nonprofit organization that supports families with adopted Chinese children, has arranged more than 1,000 return visits for families from the United States, the United Kingdom, Canada, and Australia (Ponte et al., 2010). Homeland trips usually involve outings to famous Chinese landmarks and also often include specific visits to children's orphanages and the sites of their abandonment. In a study by Ponte et al. (2010), parents listed four main reasons for returning to China for an organized heritage trip: they wanted to make China "real" for their children; to find out more information from the orphanage about children's abandonment and/or preadoption lives; to meet people who knew their child as a baby; and to give their children the chance to visibly fit in with other Chinese people. In the same study, children expressed enthusiasm over the heritage trip experience because it allowed them to connect to a past that they were too young to remember (Ponte et al., 2010). Overall, return trips help internationally adopted children from China and their parents to draw closer and meaningful connections to Chinese people, language, and culture.

\section{Research Methods}

Based on perceived gaps in the existing literature, this Major Research Paper explores the distinct form of transnationalism experienced by Chinese adoptees in Canada. To the best of the researcher's knowledge, literature on bi-cultural socialization mechanisms and culture keeping among parents of Chinese adoptees has never been pursued through the lens of immigration and diasporic transnationalism. Previous authors have successfully concluded that the increasing use of bi-cultural socialization is based on parental efforts, endorsements made by the intercountry adoption community, international conventions, and domestic 
adoption and immigration policy. Additionally, researchers have written extensively on the beneficial attachment, identity and self-esteem outcomes achieved through bi-cultural socialization mechanisms. However, these findings have never been connected to the concept of transnationalism, which is a common and thoroughly studied topic within immigration and settlement research. Consequently, this paper addresses the ways in which parents' utilize bicultural socialization mechanisms to facilitate internal community ties and transnational connections between their children and China. In doing so, the researcher attempts to present a link between parents' fostering of cultural knowledge and a resulting unique form of transnationalism that is not initially established or maintained through the efforts of the immigrant population (Chinese adoptees community).

The research question being addressed in this Major Research Paper is: How do Canadian parents of Chinese adoptees utilize bi-cultural socialization mechanisms to facilitate transnationalism among their children? In order to answer this question, a qualitative research approach was undertaken through a purposive sampling technique, self-selection and elite interview data. Data was collected through in-depth one-on-one interviews with eight parents of adopted children from China. Interviews were loosely structured using guiding open-ended questions related to participants' experiences as a parent of an adopted child from China. Semi-structured questions permitted participants to share uncensored viewpoints and facilitated a flexible mode of communication (Goss, 2010). Some interview questions were deliberately vague to prompt candid responses and generate an enriching discussion.

All eight interviews began with a brief discussion on the intercountry adoption process and participants' personal experiences during their adoption travel trip to China. This included a description of the tourist activities they took part in and any relationships they established 
with other families during the trip. These questions allowed the researcher to gain insight into the type of Chinese cultural encounter activities and cultural knowledge sought by parents while traveling in China. Additionally, the researcher encouraged a discussion on the relationships participants founded with other families during their adoption trip because the existing literature highlights the tendency for families to establish some of their in-group community ties through this intimate experience.

After this preliminary discussion on the Chinese intercountry adoption process, participants were asked questions relating to the cultural identity definitions they use to describe their daughters, the reasons behind these definition choices, as well as the methods they use to help their daughters establish their own sense of cultural identity. Participants were also invited to define the cultural identity of their immediate family as a collective group and discuss whether or not that definition had changed since adopting a Chinese child. These questions pertaining to cultural identity definitions were included in the interview discussion because they provided the researcher with information on the significance parents' accord to their daughters' cultural heritage. Additionally, questions related to participants' own sense of personal and family cultural identity highlighted their beliefs on the malleable and hybrid nature of identity construction. Furthermore, participants also addressed inquiries related to their daughters' relationships with other Chinese adoptees and the subsequent influence ingroup friendships have on their daughters' cultural identity and association with China. This discussion outlined the ways in which parents facilitate relationships within the community of families who have adopted from China in order to provide their daughters with a solid foundation of pride and respect for their birth culture. 
Moving from the topic of cultural identity, interview questions then began to focus on parents' use of bi-cultural socialization mechanisms, including the family's involvement with Chinese cultural activities or traditions and their memberships within Chinese cultural organizations. These questions were intended to gauge parents' perceptions on the importance of cultural maintenance through Chinese cultural encounter activities. In keeping with the multicultural nature of bi-cultural socialization, participants were also asked about their attitudes toward Canadian socialization. They answered questions pertaining to both the Chinese and Canadian opportunities they provide for their children. This allowed the researcher to gain insight into parents' endorsement or dismissal of bi-cultural socialization through exposure to both Chinese and Canadian cultural encounters. It was anticipated that these questions would determine the importance participants' allocate to fostering cultural awareness and pride in their child's birth heritage while simultaneously helping them adapt to the dominant Canadian culture.

The conversation then began to focus on the concept of transnationalism through questions that probed participants about their daughters' current ties to China, their desire to return to China, and their future placement within a larger community of Chinese adoptees. Participants answered questions concerning the extent to which their daughters have already established ties with China through social, cultural, emotional, or political links with their homeland. If participants revealed that their children had not already formulated some of these connections, they were asked to predict whether or not their daughters would do so as they get older. Participants also addressed inquires related to their predictions about the future sustainability of these transnational connections. Lastly, they offered their beliefs regarding the similarities and differences between the community of Chinese adoptees and the Chinese 
immigrant population in Canada. These questions were included in the interview discussion because they provided useful information on the extent to which the community of Chinese adoptees embarks on aspects of immigrant transnationalism. They also highlighted the most common form of transnational connections that are characteristic of this community. Overall, these interview questions allowed the researcher to gain insight into parents' predictions on the future of the Chinese adoptee community and how transnational ties will be sustained over time.

\section{Recruitment and Sample:}

A method of purposeful sampling, derived from criteria outlined in the research question, determined the sample size and composition of the population for this study. Coordinators of the Toronto chapter of Families With Children From China (FCC) facilitated initial contact with participants by circulating recruitment emails through member list serves. All FCC members received the same email containing identical recruitment materials. Each member made their own independent decision as to whether or not they wanted to be involved and was instructed to contact the researcher if they required further information on participation. In total, eleven parents of children adopted from China responded to the FCC recruitment emails. However, only the first eight parents to express interest in participating and who met the selection criteria were interviewed. Given the limited timeframe for this research project, a qualitative research approach was employed to gain a more in-depth understanding of the experiences, beliefs, and behaviours of a small sample of parents of Chinese adoptees. Numerically examining and analyzing a large number of cases was beyond the scope of this project. 
In order to reflect the population of Chinese adoptees in Canada, only parents who have adopted daughters from China were interviewed. Although participation was open to all parents who have chosen to adopt from China within the last twelve years, all eight volunteer participants were mothers. No adoptive fathers expressed interest in participating in the study. Six of the participants were currently married in heterosexual partnerships, while two selfidentified as single mothers. At the time of the interviews, the participants' children ranged from two to twelve years of age. Only participants with children who were between the ages of 6 months and 3 years of age during the time of adoption from China were included in the sample. Parents of children who were adopted at an older age were excluded because the goal of this research paper is to address how certain members of the Chinese adoptee community have established transnational ties without having an intrinsic longing for the homeland based on memories or pre-existing connections. It was assumed that children adopted at an older age would have substantially more existing cultural knowledge than adoptees who arrived to Canada as infants.

Lastly, given that this research paper explores the use of bi-cultural socialization mechanisms and culture keeping by parents who are racially and culturally different from their adopted Chinese children, the majority of the participants were Caucasian of Western European descent. This best reflects the demographic characteristics of Canadians who have adopted internationally from China because as Jacobson (2008) notes, intercountry adoption is largely a white, middleclass phenomenon. However, one participate in this study was a Chinese-Canadian mother who immigrated to Canada at the age of eight. This participant was married to a Caucasian Canadian and therefore, was included in the sample in order to offer 
an interesting comparative perspective related to cultural maintenance and transnationalism among trans-racial families.

\section{Analysis of Data:}

A layered coding technique was utilized to convert raw interview data into the researcher's theoretical conceptualization of bi-cultural socialization mechanisms and transnationalism. After transcribing the interview data, themes were identified by assigning conceptual markers to segments of participants' narratives. Data were deciphered and conceptualized in relation to how narratives linked to the original research question. By skimming the interview transcripts and categorizing data according to defined codes, firstlevel coding identified broad concepts such as cultural identity, community networks, and connections across borders. Codes reflected a mixture of key words outlined by participants and themes pre-existing in the literature, including "organized Chinese events", "Chinese role models", and "adoptive identity". Second-level coding divided concepts into umbrella themes and compared observations across transcriptions. Third-level coding secured categories and interpretations and ensured that all data accurately fit into the developed coding scheme. Additionally, information contradicting the categorized themes was recognized and noted.

The final stage of coding revealed six categories related to parents use of bi-cultural socialization mechanisms and the resulting impact on their daughters' degree of transnationalism through social, cultural, emotional, economic and political ties to China. The first code was labeled, Birth Roots and consisted of narratives related to the adoptive parent's cultural experiences during the adoption travel trip to China and their child's desire to return to their homeland through heritage trips. Statements related to the child's adoptive Chinese identity were categorized under the label Family and Individual Identity. This code also 
applied to narratives regarding parents' own sense of family cultural identity after adopting a child from China. Interpersonal Chinese Associations was the label used to describe the friendships adoptive parents have established and sustained through their adoption trip and as members of the community of families who have adopted from China. Additionally, this code was used to categorize narratives related to the adopted child's friendships with other Chinese adoptees and relationships with Chinese role models. The fourth code was labeled Culture Encounter and referred to statements regarding the Chinese cultural actives adoptive families pursue at home and through organized associations or segregate agencies. In-Group Community Ties was the label used to describe the current connections and networks within the community of Chinese adoptees. This code also included narratives pertaining to parents' perceptions on the future of this community, as their children mature into adolescence and adult. The last code was labeled Learning From Closed Adoption and included statements pertaining to the experiences of Korean adoptees and the movement away from the 'clean break' model of intercountry adoption. This code also applied to parents' beliefs on the differences between the communities of Korean and Chinese adoptees.

\section{Findings}

"Whenever my daughter has a project to do at school she tries to incorporate her Chinese heritage. So, this year her endangered species is the Chinese alligator and her favourite family tradition was celebrating adoption day, and when she had to do a structure, she built the Great Wall of China. They're always thinking about China and kind of working it into their everyday lives." (Mother Eight)

Eight in-depth one-on-one interviews with mothers of Chinese adoptees revealed that the community of families who have adopted children from China holds strong internal ties and transnational connections. Through online chat rooms, adoption agency newsletters, and 
pre-adoption seminars, adoptive parents are welcomed and participate in this community well before they retrieve their child from the orphanage in China. The connections between families are strengthened as adoptees begin to take part in events provided by organizations like Families With Children From China, the agency in which they were adopted from, or Chinese cultural associations and extracurricular activities. Participants outlined the ways in which the community of Chinese adoptees has assisted them with exposing their children to Chinese cultural traditions and norms. All eight of the mothers who participated in this study expressed a desire to provide their children with cultural knowledge through participation in authentic Chinese surrogate organizations and by fostering relationships with members of the Chinese immigrant community. In doing so, participants outlined the specific bi-cultural socialization mechanisms they undertake in order to submerge their children into their birth culture.

This findings section outlines mothers' narratives pertaining to their adoption travel trip experiences, the cultural identity definitions they use to describe their daughters, their use of bi-cultural socialization mechanisms, the extent to which their daughters have established transnational ties with China and their predictions on the future of the community of Chinese adoptees. In order to provide a well-rounded presentation of participants' attitudes and beliefs regarding bi-cultural socialization and transnationalism, narratives are included for each of the six analytical codes. In addition, statements from the one Chinese participant are included in a separate section entitled Interracial Family: Influence of a Chinese Mother. This segment is intended to compare the experiences of Chinese adoptees with at least one Chinese parental role model to those with non-Chinese parents. However, given that only one Chinese mother was included in the sample, findings pertaining to this participant do not provide concrete 
conclusions on adoptive families with Chinese parents. Instead, these narratives have provided interesting hypotheses that must be pursued through further research relying on a larger sample of Chinese parents of children adopted from China.

\section{Birth Roots:}

During the interview discussion concerning adoption travel trips and homeland tours of China, all eight participants highlighted the importance of homeland exposure to both adoptive parents and their children. Mothers' expressed the general desire among parents of Chinese adoptees to educate themselves about China's history and current political and cultural landscape. All of the participants agreed that adoptive parents typically pursue cultural education in order to provide their children with a sound cultural perspective of their birth country. In order to attain this goal, some parents read books and articles on China's history and cultural traditions, attend Chinese cultural workshops and seminars offered by their adoption agency, and occasionally travel to China so they can experience the country firsthand. According to one participant, "Most people who go over to adopt from China try to fit the tourist activities and cultural exposure in. Even if that can be difficult with a new baby, because they know that it's important to give their daughter that cultural perspective" (Mother Two). Based on similar statements, it was widely affirmed that while traveling to China during the adoption trip, participants attempted to learn as much about their child's birthplace as possible because of their desire to relay cultural knowledge to their children.

In addition to the cultural education obtained through the adoption travel trip, all eight participants acknowledged the importance of heritage tours in assisting them with fostering cultural pride and respect for Chinese values and norms among their children. It was agreed that roots trips provide these children with the opportunity to learn more about their personal 
history and biological family through visits to their orphanage and finding place. Six parents recognized that adoptees tend to establish emotional connections to China based on awareness of their personal stories and curiosity about their birth family. For example, one mother stated that, "...because she knows that her birth mother is in China, she knows there is some kind of connection there. Again its an emotional connection" (Mother One).

As a result of these emotional connections, one participant discussed the links she has helped facilitate between her daughter and her former orphanage through visits and monetary sponsorship.

"Kelsey and I went back. We brought things back with us. We brought money and purchased things there for the orphanage. The orphanage now has a school run out of it. Its called Believe in Me and it is run by an organization in the States called Love Without Boundaries. So, we support one of the girls in the orphanage to go to that school. We had contacted the school to find out what they needed and then we brought some supplies from here.” (Mother One)

This mother's efforts to remain connected to her daughter's orphanage reflect the aspiration among adoptive families to foster emotional and social links to China based on the child's personal story of abandonment and institutionalization.

Similarly, when discussing a recent documentary entitled Invisible Red Thread about a Canadian teenager's experience when returning to China to discover more about her birthplace, one participant acknowledged that her daughter might express similar curiosity about her heritage. "Maybe Jessica will have the same burning desire to see things with her own eyes or to go on a fact finding mission to the extent that she can. You know, see what's there. I would be behind her 100 percent" (Mother Seven). This mother notes that adoptees' curiosity about their personal history and their emotional connection to their birthplace is a natural experience that she expects to nurture as her daughter grows older. It was agreed 
among the participants that one of the best ways to address the adoptees' desire to learn more about their personal histories prior to adoption and their cultural heritage is to pursue homeland tours where the children can experience Chinese culture firsthand. All of the participants have either already undertaken return heritage trips to China or are planning on pursuing a trip once their children are old enough to understand and appreciate the significance of traveling to their birthplace. Unlike the other seven participants however, one mother felt that due to grief and suffering related to her child's abandonment, it may be of greater benefit to focus on cultural knowledge during the heritage trip, rather than her personal adoptive history.

"I know there is a dark place in her that sees that first year as a place of abandonment, suffering and not having mom and dad. And that's always going to be a part of how they see China. So, we've made a decision to go back to China next year but to go to an area completely separate from where she comes from in order to build pride in culture. Too many families just go straight back to China and take them back to the orphanage and their finding place. All these negative things. We want to go back to teach her more about her cultural heritage and build pride." (Mother Two)

This narrative confirms that in addition to providing adoptees with information on their past, parents also utilize homeland tours as a means to promote cultural pride and familiarize themselves and their daughters with an authentic understanding of Chinese heritage.

All of the participants acknowledged their attempt to paint a beautiful picture of China and Chinese culture in order to combat their daughters' relatively unpleasant and extremely emotional migration story.

"The one experience that they know of China is being abandoned and all these kids ask those questions. "Why did my birth mommy not want me? Why was I abandoned on a street? Why did I live in an orphanage for 9 months? Why did it take 9 months for you to come over and take me home?" You know, so without help that is all they have of their culture and it's negative and its personal and its difficult to deal with. I mean abandonment is the most difficult 
thing for a child to struggle with. She can't sit through a Disney movie without seeing a child being abandoned. So, it's everywhere. And I think you have to show that its not China, its not 99.9 percent of Chinese people, its not her culture and it's not who she is deep down. It's just one bad thing that happened to her." (Mother Two).

This mother's statement highlights the importance of dissociating the adoptees' Chinese heritage with their negative feelings towards abandonment and their adoptive identity. She believes that if parents do not attempt to foster pride in their daughters' cultural background, their children will always have a distressing attachment to China based on their initial relinquishment.

\section{Family and Individual Identity:}

When asked about the cultural identity definitions they employ to describe their daughters, six participants used the term "Chinese-Canadian". One mother defined her daughter's cultural identity as Canadian-Chinese, while the remaining participant stated that her daughter is "Canadian with a rich Chinese heritage" (Mother Three). Although there was a general agreement that the adoptees are "typical Canadian children" in their outlook and behaviours, all of the participants stated that their children possess a strong Chinese cultural heritage and display pride in their birth culture. Parents spoke about a type of hybrid identity based on their own ethnic origins and the adoptee's Chinese heritage. One mother exemplified this concept of hybridity when describing the cultural identity of her family as a mixture of every family member's cultural and ethnic background,

"My husband is Estonian so we just talk about how our family is a little bit Estonian, a little bit Chinese and some Canadian and that we have all of those things in our family. So, we can never be 100 percent Chinese because we're not" (Mother Four). 
This mother acknowledges that because she and her husband were not raised with a traditional Chinese influence, they cannot provide their daughter with the foundations to establish an authentic Chinese cultural identity. Instead, this family has created a blended understanding of cultural identity by incorporating aspects of every member's ethnic background.

Similarly, another participant described her desire to cultivate a balanced sense of hybrid cultural identity within her daughter so that she acknowledges and is comfortable with both her birth culture and the dominant Canadian society in which she lives.

"I think it's really important for Jessica to have both, almost as if one parent was Chinese and one parent wasn't. You would want that for the children so they have a good understanding and know that they belong and don't have feelings of falling in between the cracks, or being neither. And I think its important, not only for Jessica, but for the rest of my family, like my mom and dad as the grandparents and my brothers and their kids, to be more openminded about Chinese culture too...I just hope that Jessica can be comfortable in her skin and know that she's blended. Not blended genetically, but that she is blended by culture. She is both and has the option to maintain both. Maybe even marry someone who is Chinese. I don't know what the future holds." (Mother Seven)

This participant would like her daughter to have the option to move between two distinct cultures at ease, without feeling caught in between her Chinese heritage or her Canadian upbringing. Additionally, she acknowledges the importance of cultural acceptance among her extended family so that her daughter is content with who she is and does not wish to disown the culture of her homeland based on her racial and cultural differences with other family members.

After discussing the cultural identity definitions parents use to describe their daughters, the interview then prompted participants to outline their own individual sense of identity and the collective identity of their immediate family. Six of the participants spoke about how 
adopting a child from China has altered their own personal understanding of their cultural identity and the shared self-concept of their entire family.

"My daughter is Chinese-Canadian. First she was Chinese and then she became Canadian. So she carries the two identities together. So, when I filled out the last census, the last two census forms, I list our family as Chinese-Canadian because I don't think it would be right. Although some families would say, "well they're Canadian now". But no, we are Chinese-Canadian family. We're a bi-racial family that represents two countries." (Mother Five)

This mother acknowledges that after adopting two children from China, her own cultural identity has altered to reflect the bi-racial composition of her family. She notes the inaccuracy of labeling her family as solely Canadian due to their commitment and representation of both China and Canada.

Three participants stated that they have altered their perception of their own cultural identity because of the influence of the broader adoption community. For example, one mother spoke about the impact of the adoption system in China as well as their Canadian adoption agency in notifying perspective parents about the importance of cultural maintenance.

"It was put to us that the children were Chinese and please respect that they have a culture. But I think we got more of that during the time leading up to the adoption trip because the agencies that you go through.....we went through Children's Bridge and they had a series of seminars which were exactly about how to maintain cultural identity. They wanted to make it clear that this wasn't the same as giving birth. The children already had a history. They were between 9-18 months old. They already had a culture. They already had medical problems they may have had. So, there was no denying that they had a history before you and if you're going to be a good adoptive parent you're going to need to recognize that and deal with that from the start. And most parents do because it is a strong part of international adoption." (Mother Two)

This statement outlines the way in which the adoption community informs parents about the distinctions between adopting a child with a pre-existing personal history and giving birth to a 
biological child. Through pre-adoption seminars and the travel trip to China, it is reinforced to parents that a significant aspect of international adoption is acknowledging that the child arrives in their new home with prior cultural exposure that cannot be ignored.

\section{Interpersonal Chinese Associations:}

During the interview discussion concerning parents' efforts to form interpersonal Chinese associations with members of the Chinese adoptee community, all eight participants noted the importance of the adoption travel trip in providing them with an opportunity to form close friendships with other families adopting from China. All eight mothers affirmed that they have been successful in maintaining and growing these friendships after the adoption trip took place. One mother expressed how the small size of their family's adoption travel group influenced her ability to establish close relationships during the two-week tour, which have since continued on after returning to Canada almost two years ago.

"Yeah it was small so we did (establish friendships). We would definitely call them our friends and we've seen them several times since we've been home. We saw them every day for two weeks. We spent the entire two weeks together. Since then, I'd say we get together about three times a year. Like Chinese New Year, we've done that twice now and then summer parties at our houses and then to the zoo. We're going to have another barbeque coming up." (Mother Seven)

In addition to the significance of the adoption trip in bringing families together, all eight parents also stated that they have formed friendships through organized family events or cultural groups for adoptive families with Chinese children. Four mothers spoke about the influence of geographical location and community demographics in their ability to spend time with other adoptive families. Two of these parents reside in areas with a prominent Chinese population, as well as a large community of families who have adopted from China. 
"My younger daughter is a competitive gymnast and one of her best buddies at the gym is a Chinese adoptee. There are a ton of us in this area. So, they have swimming lessons with other adoptees and skating lessons. We used to have a playgroup here in York Region so we just got to know a lot of families from that playgroup. But even now that the girls are older, we'll see people at the grocery store or the skating rink or whatever. We all kind of know each other. There's maybe three or four girls at their school who are Chinese adoptees." (Mother Eight)

This narrative reveals that interpersonal Chinese associations are often formed through children's extracurricular activities or cultural encounter experiences that are established specifically for the community of Chinese adoptees. However, these kinds of connections are frequently facilitated through a large presence of families who have adopted from China in the region. Thus, four participants acknowledged that without a pre-existing population of Chinese adoptees, it is difficult for parents to foster extensive interpersonal Chinese associations.

Consequently, the two mothers in this sample who reside in rural communities outside of the Greater Toronto Area both agreed that their children's ability to establish friendships with other Chinese adoptees is slightly hindered by their geographical location.

"The other girls who live in the Toronto probably have more of an opportunity to make friendships with more Chinese children. Unfortunately, here we don't. Tracey is the only non-Caucasian child at her school. Even still, we probably see... at least once a month we're seeing somebody from the adoption group and we're online together almost everyday and the girls now are at the age where they're beginning to send emails to each other." (Mother Three)

This statement confirms that Chinese adoptees living in rural areas are often disadvantaged in forming interpersonal Chinese associations with other Chinese children, including Chinese adoptees. However, as this mother highlights, geographical location does not deter the community of Chinese adoptees from maintaining connections to one another through the Internet. Another mother reinforced this statement by claiming that, "Electronically it doesn't 
matter where they live. These kids will be able to connect" (Mother Five). Hence, the two mothers from rural areas agreed that although the community of Chinese adoptees is dispersed widely across the country, they remain well connected through online resources and occasional gatherings.

In addition to friendships within the community of families who have adopted from China, seven parents also spoke about their extensive efforts to form relationships with positive adult Chinese role models. It was agreed that such relationships provide Chinese adoptees with authentic cultural knowledge that their parents cannot supply on their own. One mother described the substantial effort she makes to establish friendships with Chinese adults who also have children around the same age as her daughter.

"This little girl who comes here on Mondays, and we go there, their family was not on our travel trip, but we learned about them through our social worker and they live within two kilometers of our house. So, her mom is Chinese but adopted a Chinese girl anyway. I think it's really great that Jessica goes there because they're a pretty traditional Chinese home with their cooking. Far more Chinese than Dave and I would ever be. They might play Chinese music or have Mandarin books or stuff like that. They speak Mandarin at home... And we also try really hard, when we meet people in the parks or at the swimming pool or whatever, when people are Chinese and have little ones who are her age, we try to get together... So, we have one other family that we are getting to know quite well. Mom and Dad and daughter are all Chinese and they're a biological family with no adoption and the little girl is Jessica's age. We're going to try to get together with them too because I would like Jessica to have role models of moms and dads who are Chinese." (Mother Seven).

All eight participants spoke about the cultural benefits of learning from Chinese role models who tend to be a resource of accurate information on Chinese traditions and norms. According to one mother, "we can't give our daughter's Chinese culture by celebrating Chinese New Year or doing dance and language classes. All of those are good things but that doesn't make...our children need interaction with the Chinese population" (Mother Five). 
Through similar statements, mothers acknowledged that their limited exposure to genuine Chinese socialization has made it imperative that they connect with members of the Chinese immigrant community in order to provide their daughters with positive cultural role models.

\section{Cultural Encounters:}

All of the participants reported partaking in Chinese cultural encounter activities on a weekly basis. Some of the most common cultural encounter activities that the participants reported exposing their children to were Mandarin language lessons, Chinese dance lessons, Chinese art classes, summer culture camps, Chinese cooking classes, and traditional Chinese celebrations and festivals. Seven of the participants stated that they became involved in these cultural encounter activities through their interpersonal Chinese associations. Pre-existing connections with adoption agencies, cultural organizations and families who have also adopted children from China have exposed the participants to Chinese traditions and customs.

"A lot of it is because you end up talking to someone in a café who has a Chinese daughter who you think might be adopted. And I think that's how I met one family and the mom is very active at organizing events and connecting people. She set up the Chinese classes and then she went down to the dance school in the basement of the church and asked if our Chinese girls could join. So, now the classes are integrated. They go every Saturday morning to learn Mandarin and do Chinese dance." (Mother Two)

This statement highlights the tendency for parents of Chinese adoptees to utilize their interpersonal Chinese associations while establishing surrogate agencies and extracurricular activities that expose their daughters to Chinese traditions and norms.

Four parents endorsed language maintenance as the most significant cultural encounter activity because of the importance of communication in cultural knowledge.

"We want Emily to be, if not fluent in Mandarin, we want her to have the basis to be fluent in Mandarin. We don't want her to ever lose the tones. So, she takes Mandarin lessons every week. We did culture camp when she was young 
at the Mississauga Chinese Cultural Centre but the most important thing for us is the language. We went her to have the tools. We want her to have the tools so that she can function within the Chinese culture. That if she decides that she wants to be fluent in Mandarin she won't have an accent." (Mother Four)

Through similar statements, four mothers expressed their belief that Chinese language training is an important resource for helping their daughters to successfully navigate through any barriers to Chinese cultural competency. Within the group that endorsed Mandarin lessons as the most important cultural encounter activity, it was agreed that speaking the language would allow their daughters to more comfortably associate with their Chinese heritage, while simultaneously granting them further recognition among the Chinese immigrant population.

When asked about the influence of cultural encounter activities on the future of the Chinese adoptee community, five participants expressed their prediction that any cultural exposure they provide for their children will be beneficial for them when they reach adulthood. One mother spoke about the potential for her daughter to utilize her cultural knowledge when traveling back to China through a university exchange program.

"We'd like to give her enough of her own culture so that if she chooses to go back she will be able to increase those links. Ideally I'd like her to be able to speak enough Mandarin so that she can go over there to Beijing University in some sort of exchange or immersion program where she could learn more Mandarin." (Mother Two)

This mother's narrative reflects the general desire among adoptive parents to expose their children to cultural encounter activities that will allow them to continue forming connections with China into adulthood. They would like them to have the cultural knowledge necessary to participate in Chinese society if they chose to return to their homeland. 
Although half of the participants believed that language proficiency in the most significant cultural encounter activity leading to transnationalism, it was agreed that other forms of cultural exposure also help their daughters establish connections to China. The ability to speak Mandarin is a significant facilitator of transnationalism because it offers adoptees the opportunity to pursue education and employment in China. However, participants agreed that a lack of language proficiency does not prevent adoptees from establishing other cultural and emotional transnational connections. All of participants expressed a shared belief that cultural encounters in the form of extracurricular activities, Chinese celebrations, and interaction with members of the Chinese immigrant population have the potential to lead to greater cultural association among their children. For example, one mother predicated that housing a Chinese exchange student will help her daughter learn more about her cultural background and will influence her to associate more strongly with her heritage.

"We are also taking in a Chinese student next year and I am hoping that Alexis will begin to start identifying more culturally once we have the student living here because she is starting to notice things now so I would like to expand that a little more." (Mother One)

Similarly, three other mothers spoke about the increasing presence of Chinese exchange students in their communities. It was agreed that interaction with these students would act as a form of cultural encounter experience that will enhance their daughters' connections to China.

\section{In-Group Community Ties:}

When discussing in-group community ties between Chinese adoptees, seven of the participants agreed that associating with other children with similar personal histories and 
cultural backgrounds is particularly important to their daughters. These parents purposefully fostered friendships between their children and other Chinese adoptees in their age group because they felt that their daughters enjoyed spending time with other families they can relate to. Additionally, all of the mothers acknowledged that the community is linked together based on their common experiences. According to one participant, "they are aware that they are different. So, when they are together with other kids whose parents also don't look like them, it normalizes it for them and they need that normalization" (Mother Two).

Similarly, another mother recognized how helpful it has been for her two daughters to interact with other Chinese adoptees and their families within organized community events.

"I think also to see Chinese adoptees adopted by Caucasian parents, or nonChinese parents really has helped my girls to see that even though we look unusual in our community, in the wider picture, we're really not that unusual... FCC has a huge Chinese New Years party and as the girls have gotten older...the thing is its about 500-600 families who get together to celebrate Chinese New Year and we're all families who have adopted from China... as the girls get older it's been important because that's their peer group. All these kids who don't look like their parents. They all came from China. So, they have families that look like their family." (Mother Five)

This narrative displays the ways in which in-group community ties assist Chinese adoptees in feeling less isolated and more at ease with their international adoptive status. In addition to this normalization, four of the mothers also spoke about how community connections have helped their daughters establish and sustain a strong Chinese-Canadian cultural identity. "I think that her friendship with Lexi who is culturally Chinese has been really good for her sense of self...So, then I think that for Emily having Lexi as a friend, she gets to go places with them too" (Mother Four). Based on similar statements, participants affirmed that interaction with other Chinese adoptees influences their daughters to associate more strongly with their birth heritage. 
When discussing the future sustainability of connections between Chinese adoptees in Canada, seven participants agreed that their children are members of a larger community of Chinese adoptees that will uphold its ties to one another as the children reach adulthood. For example, one mother spoke about the sibling-like relationship that some adoptees have formed with those from their same orphanage and on their adoption travel trip, "In terms of her immediate China group, they call each other 'China Sisters', so absolutely. That will be life long." (Mother Three). However, when asked about their own role in sustaining the community of Chinese adoptees, seven mothers noted that parents will eventually begin to decrease their involvement in establishing and maintaining in-group ties. “...At some point I think it will just split. In some cases we'll keep in touch with the parents and then the kids will keep in touch with each other" (Mother Four). These participants believe that as their children get older they will take on more responsibility in preserving connections with other Chinese adoptees and with the intercountry adoption community as a whole.

In addition to the changing role of parents and adoptees, one mother also noted that the community of Chinese adoptees will likely begin to evolve as the children mature into adolescence and adulthood. She believes that this group will emulate the community of Korean adoptees in North America by establishing their own adult groups.

“...what I'm hoping that they'll do is, like a lot of the Korean adoptees have done, they'll start adult groups for themselves not for their parents because one of the things I see a lot of is really intensely, almost overly involved parents. Adoptive parents tend to be a bit over involved and over protective and I think to allow your children to develop their own relationships with other adoptees, without you having to be part of that could be a really good process in their development. Because when you look at FCC a lot of the involvement is the parents wanting their kids to be involved. Which is a good thing but I think it needs to balance where the adoptees can make their own choices about that. So, I'm thinking around Toronto that kind of thing will evolve because the population or the community of families in Toronto is huge." (Mother Five) 
This mother's narrative highlights the importance of in-group community ties that are created and sustained due to the initiatives of adoptees, instead of the involvement of their parents. Furthermore, this mother highlights the possibility that the group of Chinese adoptees may begin to mirror some of the efforts of adult Korean adoptees who have organized to create a significant international community and online presence.

\section{Learning From Closed Adoption:}

When discussing the experiences of Korean adoptees who entered North America from the mid 1950s to late 1980s, six mothers expressed extensive knowledge of the 'clean break' model of intercountry adoption. They spoke comprehensively on the racism and negative identity conflicts faced by many Korean adoptees. Four of the participants agreed that the recent group of Chinese adoptees in Canada might begin to express similar frustration with their adoptive status, as they grow older.

"Jessica may grow up and say, "Why wasn't I adopted within China? Maybe that would have been better for me."... I'm prepared for some sort of backlash if she thinks we made the wrong decision on her behalf... because sometimes it feels like that. I even had my own second thoughts about adopting. I thought, "this poor child is stripped of all her nationality, all of her rights, all of her culture, all of her chance of her finding her birth parents is kind of broken when we leave the country." So that's an enormous loss for a child. Just for some agency out there or some parents like Dave and I to say "we want this child." That doesn't mean the child wants us. It's just heartbreaking that that has to be the way for us to become a family." (Mother Seven)

Despite this acknowledgment, all eight mothers expressed their belief that the community of Chinese adoptees will not be as negatively affected by the 'clean break' model of intercountry adoption as many early Korean adoptees. It was agreed that Canadian society is now more accepting of multiculturalism and adoptive parents have access to a significant number of cultural resources that were not available during the initial stages international 
adoption. For example, three mothers spoke about the group seminars with adult Korean adoptees that are occasionally provided through their adoption agency. These participants believe that the education and advice that they were provided through these types of activities have helped them avoid some of the detrimental mistakes made by the adoption community in the early phases.

"When we went to the seminars they would bring adult Korean adoptees to speak to us and I mean their experiences were very different in many ways. It's easier to provide Chinese children with a sense of their cultural heritage than it is for Koreans. Especially nowadays when Chinese culture is everywhere. I assume it would have been harder to do that ten years ago for children from Korea and also their parents wouldn't have had the same communities or even the same education...the same materials to read that we have." (Mother Two)

Similarly, another mother spoke about the differences in communication techniques endorsed by parents and the adoption community during the early and contemporary periods of intercountry adoption.

"We got some really good advice early on about just getting it all out on the table really early. Early and often. That there is no topic that you can't talk about. No secrets. Real honesty... And I think there was a trend around the time when Korean children were adopted that "well you're adopted and now lets move on." I don't think that's the case for all of this group and I think different families will have different experiences." (Mother Four)

This narrative reveals the commonly held belief that parents of Korean adoptees during the initial phase of intercountry adoption did not speak openly and honestly about their child's cultural background and adoption status. All eight mothers in this study believe that the experiences of their children differ significantly because they have actively endorsed cultural knowledge and communication about adoption.

In addition to the efforts made by parents and adoption agencies, one mother also recognized the influence of the Chinese government in undermining the 'clean break' model. 
She outlines China's ability to assist adoptive parents in maintaining cultural ties and fostering connections between adoptees and their homeland.

“... to China's credit, they have, you know, in their own interesting and unique way, made it so that it is relatively easy to maintain ties and foster connections. Perhaps that is different than the Korean situation 40 years ago. So, I don't think it would be the same." (Mother Three)

This mother acknowledges that China's endorsement of globalization has led to the movement of Chinese goods, services and people across borders. Consequently, given the substantial Chinese immigrant population in Canada, it is often easy for adoptive parents to locate and identify Chinese resources, including people, food and support groups.

\section{Interracial Family: Influence of a Chinese Mother}

In addition to the previous six categories related to bi-cultural socialization and transnationalism, the interview data also revealed an interesting comparison between the beliefs of a Chinese mother and the views of the predominant group of Caucasian adoptive parents of Chinese children. One Caucasian participant spoke about the fascinating difference between these two groups of children. This mother believes that although Chinese adoptee children with Chinese parents may have the advantage of "fitting in", Chinese families generally do not tend to get involved with the adoptive community.

"Now it will be different for the Chinese adoptees who have Chinese parents. To me, it would be interesting to see how much better they fit in because there are a number of Chinese families who have gone to China to adopt. Especially the parents who are first generation immigrants, those children will be raised with a lot of Chinese influence. More than my children. There are a number of those families because it's the best way for them to adopt because their children will look like them. But they don't tend to stay involved with the groups. They fall right off the radar right away." (Mother Five)

Narratives from the only Chinese participant in this study support this perception. When asked about the extent to which her daughters participate in the community of Chinese 
adoptees, the Chinese mother acknowledged that their family is not as well connected as those with only Caucasian or non-Chinese parents. "I don't know because they...right now they don't associate...they don't have any desire to belong...they don't question or ask if we can go to these Chinese organized parties or events so I don't know" (Mother Six).

However, despite her family's limited connection with the community of families who have adopted from China, this participant feels that her adopted children have a more authentic experience of what it is like to be Chinese. She believes that because they have a Chinese mother to identify with, her daughters will not feel caught in between their Canadian socialization and Chinese heritage.

"I think they associate with their Chinese culture more so than if both their parents were Caucasian because I think that at Chinese New Year you can put a Chinese outfit on your kid but...like I've seen some documentaries on kids that were adopted from China and it's funny because one little girl, and its kind of stayed with me, she said "I wonder what its like to be really Chinese." And I thought "well you are Chinese" but because she's coming from two parents who are both white, she is not getting the Chinese culture. So, at least with my girls, they're experiencing what being in a Chinese family is really like. I think they have a slight advantage. I think that because I look like my children they can identify with me but I think that in a household where both parents are Caucasian, they don't have anyone to indentify with. My girls can look in the mirror and they can see me... I think it will make them feel less caught in between two cultures." (Mother Six)

Furthermore, this participant expressed a belief that adopted children from China with at least one Chinese parent are less likely to experience negative issues pertaining to their adoptive and cultural identity. During the interview discussion on the early phases of intercountry adoption and the 'clean break' model of intercountry adoption, the Chinese mother dismissed the likelihood that her children would face similar experiences as early Korean adoptees. "I think that for my girls, and other children who have at least one parent who is Chinese, there will be less of that because they can associate with me and my family" 
(Mother Six). This narrative reveals the difference between a Chinese mother's reasons for dismissing the effects of the 'clean break' model and those of Caucasian parents of Chinese adoptees. Instead of focusing on Canada's endorsement of multiculturalism, the significant Chinese presence due to immigration and globalization, and the substantial resources available to adoptive parents, this participant feels that her daughters will not face the same kinds of identity conflicts as early Korean adoptees because they can racially and culturally associate with their mother and Chinese members of their extended family.

\section{Discussion}

\section{Parents’ Attitudes Towards Bi-Cultural Socialization:}

The Chinese adoptee community has rethought the assumption of a clean emotional and bodily break from China and absorption into Canadian culture. Instead of endorsing cultural assimilation, analysis of empirical interview data reveals that parents of Chinese adoptees make widespread efforts to undertake bi-cultural socialization mechanisms. Adoptive parents are informed of the benefits associated with bi-cultural socialization during the initial stages of the intercountry adoption process. Through the pre-adoption education provided by their Canadian adoption agency and the information presented by the Chinese government during the adoption travel trip, parents are advised that their children arrive to Canada with an extensive history prior adoption. Participants in this study acknowledged that their children joined the family with an existing cultural background and a personal history that is largely influenced by their abandonment and resulting institutionalization. Consequently, unlike giving birth biologically, intercountry adoption involves the expansion of a family based on the incorporation of a child with previous life experiences. Although these children might not have pervasive memories of the homeland or a similar level of existing cultural knowledge as 
immigrants who arrive to Canada later in life, intercountry adoption from China does not present a clean break from the child's country of birth. Participants in this study recognized this assertion and accepted that in order to accommodate their child's pre-existing cultural and social history, they must pursue bi-cultural socialization mechanisms that attempt to preserve their family's connection to China.

While engaging in bi-cultural socialization mechanisms, parents of Chinese adoptees foster cultural awareness and pride in their child's birth heritage while simultaneously helping them adapt to the dominant Canadian culture. According to Thomas and Tessler (2007), bicultural socialization has two general functions: "to clarify the child's role in the rest of society by socializing them in the dominant culture, while also socializing them in their birth culture so that the can attain competence and successfully negotiate between two or more cultures (p. 192)". Keeping with this understanding, participants in this study collectively acknowledged the importance of fostering respect and pride in their daughters' Chinese heritage as a means of establishing a solid foundation of cultural knowledge. It was agreed that the adoptive status of these children can represent a complicated and somewhat negative association to China based on their abandonment. In order to combat this representation, parents must make an effort to teach their children about the political and economic circumstances in China which led to their adoption. Participants highlighted the importance of dissociating their child's relinquishment with their Chinese heritage. Many parents of Chinese adoptees fulfill this ambition by encouraging their daughters to honour their birth heritage and cultivate a balanced sense of cultural identity, which acknowledges their homeland and their Canadian upbringing. 
Analysis of this empirical interview data has also revealed that cultural identity is not an entity in which individuals are born into, remaining unchanged throughout life. Gray (2007) notes that the concept of cultural identity in relation to intercountry adoption tends to be discussed in limited ways, with generalists arguments about adoptees' 'loss of culture'. This tendency reduces the complexity of identity construction by focusing on a particular ethnic category and whether or not adoptees have explored their cultural roots. Consequently, cultural identity is "narrowly framed as a bounded, unchanging entity in need of preservation rather than, a hybrid mix of positions impacted by the past and contemporary belonging" (Gray, 2007, p. 10). However, this study has confirmed that parents of Chinese adoptees tend to define their daughters' cultural identity based on their own ethnic and cultural background and their child's Chinese heritage. Participants spoke about their daughters' rich Chinese cultural heritage but also noted the cultural connections that have been founded through their family background. Unlike the 'clean break' model of intercountry adoption where adoptive parents symbolically replaced birth parents by substituting the cultural identities of the children with those of their own, participants in this study acknowledged and endorsed their child's pre-existing culture. Furthermore, keeping with Waddington's (2011) belief that cultures are interrelated and develop through interaction, participants highlighted the ways in which Chinese adoptees establish a type of malleable hybrid identity based on the cultural backgrounds of every member of their family, including their own birth heritage. Consequently, cultural identity cannot be equated with geographical location because movement across borders leads to exposure and interaction with other cultures, fostering fusion and hybridity. 
Participants in this study revealed that their efforts to pursue bi-cultural socialization mechanisms were largely based on the change in their own sense of collective family cultural identity after adopting a child from China. Once their personal identity began to reflect a stronger Chinese influence, it became important to parents to undertake bi-cultural socialization for the entire family. Six out of eight participants in this study self-identified their collective family unit as "Chinese-Canadian". In contrast, Tessler et al. (1999) describe American families who have adopted children from China using the new term, "American and Chinese" families, in order to distinguish them from traditional Chinese-American families formed through immigration and ethnic intermarriage. Despite this assertion, mothers in this study agreed that their own cultural identity had changed through the adoption process because of the new bi-racial composition of their family unit and their newfound allegiance and representation of two (or more) nations. Due to this evolution of their self-concept, bicultural socialization is perceived to be beneficial for the entire family because all members, not only the Chinese adoptee, now have a connection to China that must be fostered and preserved.

Participants also expressed a desire to pursue bi-cultural socialization mechanisms because of a general concern that their daughters would be caught in between two conflicting cultural identities if they did not provide them with sufficient exposure to their Chinese heritage. It was acknowledged that bi-cultural socialization is a necessity when adoptees are made aware of their divergence from mainstream traditional Canadian families because of their racial differences and adoptive status. Similarly, Cherot (2006) claims that complete assimilation of intercountry adoptees is not compatible with racial phenotype and constructed memories of the homeland. Due to their visible differences from both their parents and 
mainstream Canadian families, these girls must constantly explain and justify their cultural background and adoptive status. However, it was widely believed among participants that these differences might enhance their Chinese identity and encourage adoptees to associate with others within the community of families who have adopted from China.

\section{Bi-Cultural Socialization Mechanisms Pursued:}

According to Waddington (2011), cultures develop through exposure to outside influences. Based on this premise, cultural organizations and programs established by the intercountry adoption community and the Chinese immigrant population offer families an opportunity to learn about their child's birth heritage. Families With Children From China chapters and some of the larger adoption agencies help endorse bi-cultural socialization mechanisms among their members through cultural celebrations, information seminars, monthly newsletters, and the sharing of adoption research. For example, the Children's Bridge, the largest non-profit, federally incorprated adoption agency in Canada, requires that all families adopting through their agency attend a two-day adoption parenting workshop. This workshop addresses topics such as interracial issues in adoptive families and the importance of communicating to children about adoption (Gidluck and Dwyer, 2006).

Additionally, analysis of empirical interview data reveals the importance of seminars held by adoption agencies intending to warn parents of the negative outcomes resulting from the early 'clean break' model of intercountry adoption. Parents of Chinese adoptees benefit from attending workshops with adult Korean adoptees who outline the many challenges they faced while growing up in homogenous Caucasian communities with a lack of exposure to their birth culture. Adult Korean adoptees have highlighted the ways in which isolation from their birth culture and forced assimilation was damaging to their own self-esteem and to 
relations with their families. Consequently, parents of adopted children from China have taken advantage of new cultural and institutional resources that are helping to ease adoptive identity difficulties.

In addition to the resources available through the adoption community, in-group networking with interpersonal Chinese associations is another method utilized by parents when pursuing bi-cultural socialization mechanisms. Thomas and Tessler (2007) note that whereas immigrant parents tend to easily establish networks with other people like themselves, adoptive parents must work hard to connect with adults who are knowledgeable about Chinese culture. Correspondingly, participants in this study affirmed the extensive efforts they make to connect with other families who have adopted children from China as well as, biological Chinese families who have children around the same age as their daughters. Oftentimes, these relationships between adoptive parents can facilitate friendships between adoptees. The individuals with whom the child has frequent contact provide direct influence by acting as role models and initiating the child's own personal social networks in the future (Thomas and Tessler, 2007). Additionally, participants highlighted the ways in which friendships with other Chinese children and adult Chinese role models provide their daughters with authentic Chinese cultural knowledge that they themselves cannot supply on their own. Mothers acknowledged that when they have been able to network with Chinese adults and form friendships, these ethnic role models act as enablers of their children's socialization into Chinese culture. Furthermore, it was collectively agreed among participants that cultural encounter activities lead to greater cultural association among Chinese adoptees. For example, three participants in this study spoke about the ways in which interaction with 
Chinese exchange students inform adoptees about their cultural background through exposure to authentic Chinese traditions and norms.

It was determined that geographic location and community homogeneity has a negative impact on the ability of families to form personal Chinese associations with members of the Chinese adoptee community or the Chinese immigrant community. Gidluck and Dwyer (2006) have found that the majority of families who pursue international adoption reside outside of Canada's largest urban centers. In 2003, almost 70 percent of families who adopted internationally lived in smaller, much less culturally diverse communities than Vancouver, Montréal and Toronto; 40 percent of children were adopted into families living in third-tier cities and rural communities (Gidluck and Dwyer, 2006). The two participants in this study who reside in rural locations outside of the Greater Toronto Area agreed that the cultural homogeneity of their region and the significant distance between themselves and the rest of the Chinese adoptee community has created obstacles to their involvement in in-group networks. However, it was also determined that the community of Chinese adoptees has begun to maintain internal ties to members through online resources such as Websites, email, Chinese adoption chat rooms, and list serves. These participants noted that geographical location does not deter interaction and as the adoptees become old enough to maintain ingroup community connections on their own, networking will be facilitated through the Internet.

Despite the significant use of bi-cultural socialization mechanisms among participants in this study, the mothers offered very few examples of the types of Canadian cultural opportunities they provide for their children. As Scherman (2010) argues, the idea that mainstream culture identification might be as important as birth country identification to the 
adopted child's adjustment and balanced sense of cultural identity, has received very little research attention. The existing literature on bi-cultural socialization among families with internationally adopted children is limited by its focus on birth culture exposure. Similarly, when participants in this study were asked about the Canadian aspects of the bi-cultural socialization mechanisms they pursue, mothers tended to focus on their family's values instead of specific cultural encounter activities, interpersonal associations and community ties. However, Tessler et al. (1999) note that because Chinese adoptees are exposed to the mainstream and dominant language, values and culture on a daily basis, there is less need for parents to make an exceptional effort to accomplish the Canadian component of bi-cultural Chinese-Canadian competence. Consequently, participants in this study may have avoided providing examples of the Canadian cultural socialization activities they take part in because they do not have to make extensive efforts to actively seek these opportunities.

\section{Transnational Ties:}

Analysis of the empirical interview data reveals that like many other immigrant groups, Chinese adoptees are experienced and attached to both their homeland and receiving country. This attachment is facilitated through adoptive families, the institutionalized adoption community in Canada and the Chinese government who actively attempt to supply some of the network, culture and capital obtained through other channels by other diasporic groups. Participants in this study highlight the significant collective cultural consciousness

among Chinese adoptees who form connections based on their distinctiveness from mainstream society, a common adoptive history and a mutual longing for cultural knowledge. However, Canada's Chinese adoptee diaspora differs from the Chinese immigrant population 
because the creation and maintenance of transnational ties are largely the result of adoptive parents' efforts to submerge the child into their birth culture.

Participants in this study have confirmed that Chinese adoptees arrive to an environment in which networks of families with similarly adopted Chinese children are already in place. This environment is the result of efforts made by parents and the adoption community who understand the importance of in-group community connections and transnational networks to China. Gray (2007) argues that contemporary adoption discourses are based on the premise that adopted children are 'rooted' and have 'primal connections' to his/her biological family and birth place. Similarly, Kim (2007) argues that the term "transnational adoption" references the ways in which these adoptions are not simply one-way journeys but also entail "ongoing, crisscrossing flows in multiple directions, in space that is both real and virtual" (p. 500). Chinese adoptees express allegiance to constructed memories and myths about the homeland that are idealized through the efforts of their parents. Accordingly, transnational connections between Chinese adoptees and their birthplace are a result of parents' use of bicultural socialization mechanisms.

Miller-Loessi and Kilic (2001) suggest that since a diaspora is transnational in scope and is socially constructed by the daily activities of immigrants, the community of families with adopted Chinese daughters shows signs of diasporic transnationalism. Within diasporic communities there is a constant exchange between or among spatially separated populations. Transnational communities are constructed from in-group connections and international ties between a widely dispersed diaspora and the homeland. In order to maintain internal connections, participants in this study revealed that adoptive parents of Chinese children form friendships with other individuals within the community of families who have adopted from 
China. Participants agreed that these relationships are initiated because of their family composition and similar child-rearing experiences. Furthermore, parents of Chinese adoptees actively link their children with other adoptees because of a belief that they will identify and enjoy interacting with one another based on their similar adoption experiences. Participants highlighted the ways in which in-group community ties offer information on adoptees' racial and ethnic heritage through cultural encounter activities while also affording them a sense of normalcy through the knowledge that families formed through intercountry adoption are common.

In addition to the benefits associated with in-group connections, participants in this study stated that their use of bi-cultural socialization mechanisms is part of a wider goal to provide cultural exposure that will be advantageous to their children into adulthood. Parents hope that by forming interpersonal Chinese associations and exposing their children to cultural encounter activities, they will provide them with the Chinese cultural knowledge necessary to move between cultural associations comfortably. Parents would like their children to be proficient in Chinese culture in order to successfully adjust to life in China if they choose to return for future study or employment opportunities. However, although all of the participants reported a desire to return to China as part of a heritage tour, they acknowledged that the likelihood of their daughters returning to China permanently is low. Similarly, Miller-Loessi and Kilic (2001) argue that comparable to second, third and fourth generation Chinese immigrants, the probability of Chinese adoptees permanently returning to China is weak. Despite this, it is typically the idea of a return to the homeland that is powerful in diasporic consciousness, rather than a real 'return' (Miller-Loessi and Kilic, 2001). Therefore, participants in this study have confirmed that their daughters have constructed an 
idealized image of China, and hope to return temporarily to experience their birth culture firsthand. According to Gray (2007), the desire of a homeland unifies the international adoption community. Consequently, heritage tours cement friendships with other adoptees and foster transnational friendships, which facilitate ongoing communication and future journeys to China.

Participants' narratives have revealed that cultural and emotional connections to China are the most dominant form of transnational ties established and maintained by parents of Chinese adoptees. Similar to other immigrant groups, the transnational community of Chinese adoptees preserves ties to their homeland based on constructed memories of their personal pre-immigration history and emotional connections to their biological family members in China. However, unlike other newcomer communities, longings of the homeland are imagined and created through the efforts of adoptive parents. Dorrow and Lepatsky (2006) claim that intercountry adoption is an exceptional form of Canadian family class immigration because the adopted child cannot legally sustain ties to his/her biological family. Although this is significantly different from the experiences of other newcomers who maintain close ties to friends and family in their homeland, Chinese adoptees have established similar connections through constructed memories and longings for cultural knowledge. These transnational emotional connections are largely based on parents' efforts to inform their children of their own personal adoption history, which often translates into constructed links to their biological family.

When discussing the longevity of transnational ties between Chinese adoptees and their homeland, participants agreed that their children are members of a larger community of Chinese adoptees that will sustain their internal connections and ties to China into adulthood. 
For example, mothers highlighted the sister-like relationship between many Chinese adoptees who were adopted from the same orphanage or who traveled together during the adoption trip. Additionally, parents are occasionally successful in connecting and fostering strong relationships between adoptees who were orphanage crib-mates, often referring to these children as "China Sisters". It was agreed that these relationships will continue on as the adoptees reach adulthood because of the close bonds that have been formed through their early adoption history and continued interaction within the community of Chinese adoptees.

Participants in this study affirmed their belief that the Chinese adoption community will begin to evolve as the children mature into adulthood. As the adoptees get older, parents will decrease their involvement in maintaining internal and transnational ties and the adoptees will begin to sustain in-group community connections. Carlson (2011) notes that as adoptees develop autonomy during adolescence and adulthood, they begin to engage in more selfinitiated and deeper-level cultural encounter experiences such as traveling to their birth country and searching for their biological family. Consequently, this community may begin to emulate other groups of adult intercountry adoptees in North America by establishing their own adult adoptee organizations and networks. Some international adoptee youth and adults have established online organizations to help them maintain connections within the community and share information. Utilizing these online communities, many international adoptees have begun to reconnect with their origins by networking with other adoptees and forming relationships based on common goals and a collective history. Cherot (2006) claims that global flows of communication including online list serves, instant messaging, and multiple user chat rooms have facilitated international adoptees' ability to join a transnational community of adoptees and connect with larger diasporas all over the world. For example, 
both the Filipino and Vietnamese Adoptee Networks act as a social avenue for adoptees to interact, share information and organize events online.

\section{Limitations and Suggestions for Further Research}

Consistent with concerns of sampling in most qualitative studies, the sample size for this research paper creates challenges to the researcher's ability to present generalized results. However, instead of offering broad overviews about the entire Chinese adoptee diaspora in Canada, this study portrays a highly specific analysis of the target population. Although it would have been beneficial to undertake a mixed methods research approach in order to compensate for the weaknesses of such a small sample size, the purpose of this study was to gain a more in-depth understanding of the experiences, beliefs, and behaviours of a small sample of parents of Chinese adoptees. Also, due to the limited time frame and other program requirements, it was imperative that recruitment and interviews for this study were conducted during a one-month span, insufficient in generating a large and representative sample.

This paper is also limited by the purposive sampling recruitment and self-selection technique. Recruitment through FCC has restricted this research to those who were exposed to the relevant form of media, were concerned with bi-cultural socialization within intercountry adoption and were interested and motivated to participate in the study. Consequently, the sample may over represent parents with an interest in fostering connections to their children's birth culture simply due to their membership in FCC and their willingness to contribute to this study. Correspondingly, the sample may not represent adoptive parents who deliberately choose to avoid participating in these types of Chinese cultural organizations. Parents who are not active members of the Chinese adoption community may place less significance on bicultural socialization mechanisms and therefore their children may not possess transnational 
ties to China. However, recruitment through FCC allowed the researcher to contact parents with unique understandings and stories relating to the experiences of Chinese adoptees in Canada. Given that the community of Chinese adoptees is relatively smaller and more geographically dispersed than other immigrant communities in Canada, it would have been extremely difficult to locate participants without using a purposive sampling method.

The purposive sampling recruitment and self-selection technique has also created a challenge regarding the gender imbalance in the sample for this study. It is possible that a sample consisting of only women has distorted the research findings. In a study by Hanigan Scroggs and Heitfield (2001) it was discovered that mothers generally afford greater importance to and participate more frequently in cultural activities with their internationally adopted children than fathers. If this is a comprehensive characteristic of intercountry adoptive families as a whole, it is possible that the sample used for this study is a further overrepresentation of parents who endorse bi-cultural socialization and culture keeping.

In addition to these recruitment limitations, the comparison this paper presents between the beliefs of one Chinese mother and the views of the predominant group of Caucasian adoptive parents of Chinese children is also restricted by the small sample size. Given that only one Chinese parent participated in this study, it is impossible to draw concrete conclusions on the experiences of Chinese-Canadian families who adopt from China. However, interesting hypotheses can be drawn from the narratives provided by participants who discussed their beliefs on the differences in experiences between Chinese adoptees with at least one Chinese parent to those with non-Chinese parents.

Among both Caucasian and Chinese participants it was agreed that Chinese families often do not maintain their involvement with the Chinese adoption community after they 
receive their daughters. It was believed that Chinese families tend to break away from the adoption community because they already possess the cultural resources necessary to provide bi-cultural socialization. Similarly, Carlson (2011) argues that cultural socialization from trans-racial adoptive families is oftentimes more extrinsic and superficial than in same-race families because the responsibility for socialization rests largely with white parents who do not share the child's ethnic and racial heritage. Given that they can racially and culturally associate with members of their own family, these children will be provided with authentic exposure to Chinese culture and may not be forced to redefine their cultural identity by seeking further cultural knowledge into adulthood. Further qualitative and quantitative research that relies on a larger sample of the population is needed to address the hypothesis that adopted children with at least one Chinese parent have a more authentic understanding of Chinese cultural values, norms and traditions.

Researchers could also expand on this topic by examining whether or not Chinese adoptees with at least one Chinese parent feel caught in between their birth heritage and Canadian socialization in the same way that is common to other international adoptees. Interview data with one Chinese mother revealed that these children may be less likely to suffer from negative adoptive and cultural identity issues because they can identify with a parent and extended family members who share their Chinese heritage. This finding should be further explored by examining the beliefs of a larger sample of Chinese parents regarding the likelihood that their daughters will experience the same type of resentment towards their adoptive status that has been reported by many adult Korean adoptees. Further research would offer an interesting discussion on the difference in transnational ties between Chinese adoptees with Chinese parental role models and those who are raised by non-Chinese parents. 
Unlike the majority of Chinese adoptees with Caucasian parents, further research may reveal that adoptees with Chinese parents establish transnational connections predominately based on associations and interaction with their Chinese relatives.

In addition to exploring these hypotheses, research on the transnational connections between children adopted from China and their homeland needs to be expanded by examining a large sample of adolescent and adult Chinese adoptees. The existing literature relies predominately on interview data and survey responses from adoptive parents, rather than the adoptees themselves. It is often difficult for researchers to differentiate the experiences of adopted children from what emotions and behaviours their parents might attribute to the child. Consequently, it is possible that this study is limited by its exclusive reliance on parental narratives that may not reflect a completely accurate portrayal of the Chinese adoptee transnationalism. Given that the early cohorts of intercountry adoptees from China are now in their teenage years, it is important to gather research on their own beliefs regarding the transnational ties they have maintained. Research that relies on a large sample of Chinese teenagers and adults who were adopted into Canadian families would generate a more accurate understanding of the form of transnationalism experienced by Chinese adoptees in Canada.

\section{Conclusion}

This Major Research Paper has outlined the ways in which parents' utilize bi-cultural socialization mechanisms to facilitate internal community ties and transnational connections between their children and China. In doing so, the researcher has attempted to present a link between parents' efforts to foster Chinese cultural knowledge and a form of transnationalism that is common among other immigrant groups. Through a qualitative research approach 
based on purposive sampling, self-selection and data from eight in-depth one-on-one interviews with mothers of Chinese adoptees, it was revealed that the Chinese adoptee community holds significant internal connections and transnational ties. These networks are facilitated through adoptive families and the institutionalized adoption community in Canada. Consequently, Chinese adoptees experience a unique form of transnationalism that is not characteristic of the Chinese immigrant population in Canada because their ties to the homeland are based on parents' efforts to pursue bi-cultural socialization mechanisms.

Intercountry adoption from China does not present a clean break from the child's birthplace because they join their new families with prior Chinese cultural exposure and a preexisting history of abandonment and institutionalization. Parents recognize this assertion and understand that in order to accommodate their child's cultural and social history, they must pursue bi-cultural socialization mechanisms that preserve their family's connection to China. Parents often participate in bi-cultural socialization mechanisms because of their daughters' hybrid cultural identity and a change in their own sense of collective family cultural identity after adopting a child from China. Additionally, many parents are concerned that their daughters would be caught in between two conflicting cultural identities if they did not provide them with sufficient exposure to their Chinese heritage. Generally, parents hope that by forming interpersonal Chinese associations and exposing their children to Chinese cultural encounter activities, they will provide them with the cultural knowledge necessary to move between cultural associations comfortably. Therefore, the use of bi-cultural socialization mechanisms is part of a wider goal to provide cultural exposure that will benefit their children into adulthood. Parents would like their children to be proficient in Chinese culture in order to 
successfully adjust to life in China if they choose to return as part of a heritage tour or to pursue education and employment opportunities.

In order to attain these goals, parents of Chinese adoptees utilize resources provided by cultural organizations and programs established by the intercountry adoption community or the Chinese immigrant population to help them learn about their child's birth heritage. In addition, parents often pursue in-group networking with interpersonal Chinese associations. Friendships with other Chinese children and adult Chinese role models provide their daughters with authentic Chinese cultural knowledge that they cannot supply on their own. These ethnic role models act as enablers of their children's socialization into Chinese culture. Overall, in-group community connections offer information on children's racial and ethnic heritage through cultural encounter activities while also affording them a sense of normalcy through exposure to families similar to their own. However, geographic location and community homogeneity has a negative impact on the ability of families to form personal Chinese associations and in-group community connections. Despite their disadvantage, families living in rural locations have been successful at maintaining internal ties through online resources.

Similar to other immigrant groups, the transnational community of Chinese adoptees preserves ties to their homeland based on constructed memories of their personal preimmigration history and emotional connections to their biological family members in China. Consequently, cultural and emotional connections to China are the most dominant form of transnational ties established and maintained by parents of Chinese adoptees. Parents assist their daughters with constructing memories and sustaining longings for cultural knowledge. They often inform their children of their personal adoption history and foster emotional links 
to China based on knowledge of the child's biological family. However, the Chinese adoption community will evolve as the adoptees mature into adulthood because parents will begin to decrease their involvement in maintaining internal and transnational ties and adoptees will take the initiative to sustain connections. In doing so, the community of Chinese adoptees may begin to follow other groups of adult international adoptees by establishing a significant online presence.

The unique form of transnationalism experienced by intercountry adoptees is an important area of immigration research because Canadian families continue to adopt about 2,000 children internationally per year. Although, such adoptions represent a small percentage of the total annual immigration flow, the diaspora of international adoptees is expanding at the same time that early adoptees are maturing into adolescence and adulthood. Furthermore, this is a significant area of research because intercountry adoption expands the scope of transnationalism to include individuals who were too young during the time of migration to possess significant memories of the homeland. Instead, these memories have been imagined and constructed through parents' use of bi-cultural socialization mechanisms. Additionally, this research reveals that transnational connections do not completely depend on pre-existing links with friends and family, economic ties, or political and social involvement in the country of origin. Therefore, recognizing Chinese adoptees as a transnational diaspora in Canada demonstrates that it is possible for immigrants to be attached to two or more places simultaneously while being raised by parents who have not been socialized within the culture of their homeland. 


\section{Appendix A: Participant Recruitment Letter}

\section{RYERSON \\ UNIVERSITY}

Thursday, May 10, 2012

This letter is an invitation to consider participating in a study I am conducting as part of my Master's degree in the Immigration and Settlement Studies program at Ryerson University. This research study will be pursued under the supervision of Dr. Francis Hare, Professor, School of Child and Youth Care and Director, MA Program in Immigration and Settlement Studies. I would like to provide you with more information about this project and what your involvement would entail if you decide to take part.

This study will explore the ways in which Chinese adoptees in Canada are emotionally, socially, culturally and/or politically attached to two or more places simultaneously. The purpose of this study is to gain a better understanding of parents' role in helping their adopted children develop ties with their homeland. Although similar studies have been conduced in the United States, the Canadian literature on the experiences of Chinese adoptees is limited. Additionally, most of the existing research on this topic focuses on post-adoption adjustment issues and little emphasis is placed on parental perspectives. Therefore, this study will fill a gap in the literature regarding Canadian adoptive parents' beliefs on cultural maintenance and how their behaviour influences the ability of Chinese adoptees to establish ties with their homeland.

Participation in this study is voluntary. It will involve an interview of approximately one hour in length to take place in a mutually agreed upon location. You may decline to answer any of the interview questions if you so wish. Further, you may decide to withdraw from this study at any time without any negative consequences by advising the researcher. With your permission, the interview will be audio recorded to facilitate collection of information, and later transcribed for analysis. Shortly after the interview has been completed, I will send you a copy of the transcript and/or recordings to give you an opportunity to confirm the accuracy of our conversation and to add or clarify any points that you wish. All information you provide is considered completely confidential. Your name will not appear in any report resulting from this study; however, with your permission anonymous quotations may be used.

If you are interested in participating in this study or would like further information to assist you in your decision, please contact me at 416-979-5000 ext. 6200 mailbox 2 or by email at meaghan.symington@ ryerson.ca. 
I would like to assure you that this study has been reviewed and received ethics clearance through the Research Ethics Board at Ryerson University. However, the final decision about participation is yours.

I very much look forward to speaking with you and thank you in advance for your assistance in this project.

Yours Sincerely,

Meaghan Symington

Student Investigator 


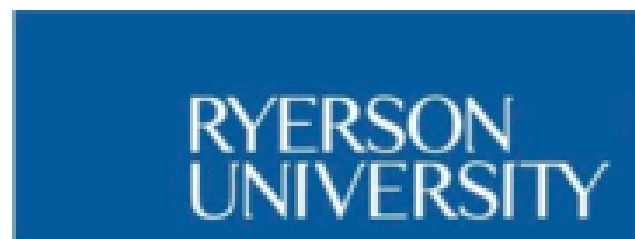

\section{We are currently enrolling participants in a research study that will explore parents' role in facilitating ties between Chinese adoptees and their birth culture.}

\section{What is the purpose of the study?}

This study will explore the ways in which Chinese adoptees in Canada are emotionally, socially, culturally and/or politically attached to two or more places simultaneously. The purpose of this study is to gain a better understanding of parents' role in helping their adopted children develop ties with China.

\section{Who can participate?}

All prospective participants must be Canadian parents of a daughter adopted from China within the last twelve years. All of the children must have been between the ages of 6 months to 3 years at the time of adoption.

What do I have to do if I decided to participate in the study?

Participants will be asked to partake in an in-depth one-on-one interview of approximately two hours in length. Interviews will take place in a mutually agreed upon location.

This research is being conducted by:

Meaghan Symington, Candidate for MA in Immigration and Settlement Studies, Ryerson University.

Please contact Meaghan for additional information or if you are interested in participating in this study:

\section{Meaghan Symington} 416-979-5000 ext. 6200 mailbox 2 meaghan.symington@ryerson.ca 


\section{Appendix C: Interview Guide}

The purpose of this study is to gain a better understanding of parents' role in helping their adopted children develop ties with their homeland. I will be asking you open-ended questions related to your experience with intercountry adoption from China and your adoption trip. I will also be asking you about the cultural identity definitions you use to describe your daughter(s), the reasons behind these definition choices, as well as the methods you use to help your daughter(s) establish their cultural identity. Lastly, you will be asked about the extent to which your daughters have established ties with China through social, cultural, emotional, or political links with her homeland. You are not obligated to answer any questions you do not wish to answer. There is no right or wrong answer to any of the questions I will be posing. Through these questions, I am not implying that cultural exposure or links to China are either beneficial or harmful in any way. This will take approximately one hour to complete and with your permission, I will be taking notes and recording our discussion.

\section{Intercountry Adoption Process/Experience}

1) Can you please describe your adoption trip experience? How long were you required to spend in China? What types of activities did you take part in, both before and after you retrieved your daughter from the orphanage?

2) Did you establish friendships with any of the other parents on the adoption trip?

3) If yes, are you still in contact with the friends you made during the adoption trip?

4) Before becoming a legal guardian of your daughter were you required to make an oath to Chinese officials regarding her cultural heritage? What did this entail?

\section{Cultural Identity}

1) How would you define your daughter's cultural identity?

2) Why have you chosen this definition?

3) How would you define the cultural identity of your immediate family, as a collective group? Why would you use this definition?

4) Are there identity struggles that you anticipate or hope to prevent as your child develops?

5) Does your daughter associate with her Chinese heritage? Does she enjoy expressing her Chinese roots?

6) If yes, how does she present her Chinese identity? 
7) If no, why do you think this is the case?

8) Does your daughter have friends who are also Chinese adoptees?

9) If yes, have these friendships helped her associate with her Chinese heritage?

\section{Bi-cultural Socialization Mechanisms}

1) Do you believe that it is important for your family take part in Chinese cultural activities or traditions? Why or why not?

2) Are you a member of any Chinese cultural organization?

3) What type of cultural activities do you take part in at home? (not necessarily only Chinese cultural practices/traditions).

4) What is your attitude toward Canadian socialization? What Canadian opportunities do you provide your child?

\section{Transnationalism}

1) Does/do you daughter(s) currently express any ties to China, in the form of social, political, cultural, or emotional links? If yes, how is this displayed?

2) Do you foresee your daughter(s) becoming a member of a larger community of Chinese adoptees when she/they is older? Why or why not?

3) If yes, what would draw these individuals together?

4) In general, do you believe that the community of Chinese adoptees is similar to the Chinese immigrant community in Canada?

5) Do you or your daughter have a desire to return to China? 


\section{Bibliography}

Boates, C. (2008). Nice and Warm. In A. Rauhala (Ed.), The Lucky Ones: Our Stories of Adopting Children From China, (155-163). Toronto: ECW Press.

Berbery, M and K. O'Brien. (2011). Predictors of White Adoptive Parents' Cultural and Racial Socialization Behavious With Their Asian Adopted Children. Adoption Quarterly, 14(1) 284-304.

Bergquist Ja Sook, K. (2003). Expanding the Definition of Asian Diasporic Studies: The Immigrant Experiences of Korean Adoptees. Journal of Immigrant and Refugee Services, 1(4), 21-39.

Brown, J. (2010). What The Children Have Taught Me. In D. Jacobs, I. Ponte and L.K Wang (Ed.), From Home to Homeland: What Adoptive Families Need to Know Before Making a Return Trip to China. New York: Yeong and Yeong Book Company.

Carlson, R. (2011). Seeking the Better Interests of Children With a New International Law of Adoption. New York Law School Law Review, 55: 733-780.

Carstens, C. and M., Juliá. (2000). Ethno-racial Awareness in Intercountry Adoption: US Experiences. International Social Work, 43(1) 61-73.

Cherot, N. (2006). Transnational Adoptees: Global Biopolitical Orphans or an Activist Community? Culture Machine, 8(1) 46-54.

Citizenship and Immigration Canada (2011). Facts and Figures 2010 - Immigration Overview: Permanent and Temporary Residents. Retrieved from http://www.cic.gc.ca/english/resources/statistics/facts2010/index.asp

Dorrow, S and T., Lepatsky. (2006). Intercountry Adoption: An "Exceptional" Form of Immigration? In M. VanderPlaat (Ed.), Canadian Issues: Immigration and Families, (61-64). Metropolis.

Dorrow, S. (2006). Transnational Adoption: A Cultural Economy of Race, Gender, and Kinship, New York: New York University Press.

Dowling, M. and G. Brown. (2009). Globalization and International Adoption From China. Child and Family Social Work, 14(3) 352-361.

Freundlich, M. and J.K Lieberthal. (2000). The Gathering of the First Generation of Adult Korean Adoptees: Adoptees' Perceptions of International Adoption. The Evan B.Donaldson Adoption Institute. Retrieved on February 18, 2012, from http://www.adoptioninstitute.org/proed/korfindings.html 
Gidluck, L. and S.C. Dwyer. (2006). Families of Asian Children Adopted by White Parents: Challenges of Race, Racism and Racial Identity in Canada. In Our Diverse Cities, Number 2. (Ed.), J.S, Frideres. $11^{\text {th }}$ International MetropolisConference, Paths and Crossroads: Moving People, Changing Places. October $26^{\text {th }}, 2006$.

Goss, K. 2010. White Envy and Piggy-Backing Privilege: Exploring Adult KoreanTransracial Adoptees' Identities in the Canadian Context. Toronto: MRP presented to Ryerson University in partial fulfillment of MA in the program of Immigration and Settlement Studies.

Gray, K. M. (2007). 'Bananas, Bastards and Victims?' Hybrid Reflections on Cultural Belonging in Intercountry Adoptee Narratives. Newcastle: Dissertation presented to The University of Newcastle in partial fulfillment of the degree of Doctor of Philosophy.

Hanigan Scroggs, P. and H. Heitfield. (2001). International Adopters and Their Children: Birth Culture Ties. Gender Issues, (3) 3-30.

Hiebert, D. (2000). Cosmopolitainism at the Local Level: Immigrant Settlement and the Development of Transnational Neighbourhoods. Research on Immigration and Integration in the Metropolis, Working Paper Series No. 15.

Jacobson, H. (2008). Culture Keeping: White Mothers, International Adoption and the Negotiation of Family Difference. Nashville: Vanderbilt University Press.

Kim, E. (2007). Our Adoptee, Our Alien: Transnational Adoptees as Specters of Foreignness and Family in South Korea. Anthropological Quarterly, 80 (2) 497-531.

Lee, R. (2006). Overlooked Asian Americans: The Diaspora of Chinese Adoptees. Asian Journal of Counselling, 13(1), 51-61.

Levitt, P., J. DeWind and S. Vertovec. (2003). International Perspectives on Transnational Migration: An Introduction. The International Migration Review, 37(3) 565-575.

Lovelock, K. (2003). Intercountry Adoption as a Migratory Practice: A Comparative Analysis of Intercountry Adoption and Immigration Policy and Practice in the United States, Canada and New Zealand in the Post WWII Period. The International Migration Review, 34(3), 907-949.

Luo, N. and D. M. Smolin. (2005). Intercountry Adoption and China: Emerging Questions and Developing Chinese Perspectives. Cumberland Law Review, 35(3) 597-618.

Miller-Loessi, K and Z., Kilic. (2001). A Unique Diaspora? The Case of Adopted Girls from the People's Republic of China. Diaspora, 10(2), 243-260. 
Oesterle, H. (2006). International Adoption: Cultural Socialization and Identity Development. Brigham Young University. Submitted in partial fulfillment of the requirements for the degree Master of Science.

O'Halloran, K. (2009). The Politics of Adoption: International Perspectives on Law, Policy and Practice. Springer Science: Queensland, Australia.

Ponte, I., L, Wang and S, Pen-Shian Fan. (2010). Returning to China: The Experience of Adopted Chinese Children and Their Parents. Adoption Quarterly, 13(1) 100-124.

Preston, V., A. Kobayashi, and M. Siemiatycki. (2006). Transnational Urbanism: Torontoat a Crossroads. In V, Satzewich, and L. Long. (Ed.), Transnational Identities and Practices in Canada, (91-110). Vancouver: University of British Columbia Press.

Quiroz, P. A., (2008). Transnational Adoption: Reflections of the "Diaper Diaspora" on Reconfiguring Race in the USA. International Journal of Sociology, 28(11/12), 440457.

Randolph, T. and M. Holtzman. (2010). The Role of Heritage Camps in Identity Development Among Korean Transnational Adoptees: A Relational Dialectics Approach. Adoption Quarterly, 13(2) 75-99.

Scherman, R.M. (2010). A Theoretical Look at Biculturalism in Intercountry Adoption. Journal of Ethnic and Cultural Diversity in Social Work, 19(2) 127-142.

Selman, P. (2002). Intercountry Adoption in the New Millennium: The "Quiet Migration" Revisited. Population Research and Policy Review, 21(1), 205-225.

Selman, P. (2006). Trends in Intercountry Adoption: Analysis of Data From 20 Receiving Countries, 1998-2004. Journal of Popular Research, 23 (2) 183-204.

Selman, P. (2009). The Rise and Fall of Intercountry Adoption in the $21^{\text {st }}$ Century. International Social Work, 52(5) 575-594.

Song, S.L. and R.M. Lee. (2009). The Past and Present Cultural Experiences of Adopted Korean American Adults. Adoption Quarterly, 12(1) 19-36.

Tan, T. X and M. J., Nakkula. (2008). White Parents' Attitudes Toward Their Adopted Chinese Daughters' Ethnic Identity. Adoption Quarterly, 7(4), 57-76.

Tessler, R., G. Gamache and L. Liu. (1999). East Meets West: Americans Adopt Chinese Children. Connecticut: Bergin \& Garvey. 
The Hague Conference on Private International Law. (1993). The Hague Convention on protection of children and co-operation in respect of Intercountry Adoption (1993). Retrieved on May 20, 2012 from

www.hcch.net/index_en.php?act=conventions.pdf\&cid=69.

Thomas, K. and R. Tessler. (2007). Bicultural Socialization Among Adoptive Families: Where There is a Will, There is a Way. Journal of Family Issues, 28 (9) 11891219.

Volkman, T. A. (2003). Embodying Chinese Culture: Transnational Adoption in North America. Social Text, 21(1), 29-55.

Vonk, E and R. Massatti. (2008). Factors Related to Transracial Adoptive Parents' Levels of Cultural Competence. Adoption Quartetly, 11(3) 204-226.

Vonk, M.E, J. Lee and J. Grolley-Simic. (2010). Cultural Socialization Practices in Domestic and International Transracial Adoption. Adoption Quarterly, 13(3-4) 227-247.

Waddington, G. (2011). A New Class of Persons: Intercountry Adoptees and Postcolonial Theories of Cultural Hybridity. Creighton International and Comparative Law Journal, 1(1) 81-99.

Wong, L. and V. Satzewich. (2006). Introduction: The Meaning and Significance of Transnationalism. In V, Satzewich, and L. Long. (Ed.), Transnational Identities and Practices in Canada, (1-15).Vancouver: University of British Columbia Press.

Worotynec, Z.S. (2006). Child Interrupted: International Adoption in the Context of Canadian Policy on Immigration, Multiculturalism, Citizenship, and Child Rights. CERIS Working Paper No.46.

Zhang, D. (2010). Intercountry Adoption: Clashing Colors of a Family Portrait. UCLA Asian Pacific American Law Journal, 15 160-190.

Zhang, Y. and G.R. Lee. (2011). Intercountry Versus Transracial Adoption: Analysis of Adoptive Parents' Motivations and Preferences in Adoption. Journal of Family Issues, 32(1) 75-98. 